\title{
The azimuthal extent of three flux transfer events
}

\author{
R. C. Fear ${ }^{1}$, S. E. Milan ${ }^{1}$, A. N. Fazakerley ${ }^{2}$, E. A. Lucek $^{3}$, S. W. H. Cowley ${ }^{1}$, and I. Dandouras ${ }^{4}$ \\ ${ }^{1}$ Department of Physics and Astronomy, University of Leicester, Leicester, LE1 7RH, UK \\ ${ }^{2}$ Mullard Space Science Laboratory, University College London, Holmbury St. Mary, Dorking, Surrey, RH5 6NT, UK \\ ${ }^{3}$ Blackett Laboratory, Imperial College, Prince Consort Road, London, SW7 2BZ, UK \\ ${ }^{4}$ CESR/CNRS, 9 Avenue du Colonel Roche, B.P. 4346, 31028 Toulouse Cedex 4, France
}

Received: 26 February 2008 - Revised: 20 May 2008 - Accepted: 27 May 2008 - Published: 5 August 2008

\begin{abstract}
In early 2006, the Cluster spacecraft crossed the dayside magnetopause twice each orbit with the spacecraft at their largest separation of the entire mission $(\sim 10000 \mathrm{~km})$. In this paper, we present in situ observations at this separation size of flux transfer events (FTEs), which are a signature of transient or time-varying magnetopause reconnection. We study a magnetopause crossing on 27 January 2006; for half an hour, the tetrahedron of Cluster spacecraft straddled the magnetopause and during this time a large number of flux transfer events were observed. Three particular FTEs were observed by all four spacecraft, enabling it to be shown that individual FTEs at the magnetopause can extend azimuthally for at least $10000 \mathrm{~km}$. By combining the Cluster tetrahedron geometry with the observed velocity of the FTEs, it can be shown that the poleward extent of one FTE is significantly smaller than its azimuthal extent. The location of the Cluster spacecraft when they observed this FTE suggests that it is inconsistent with the simple interpretation of an "elbowshaped" flux tube. The FTE's azimuthal extent suggests that it was more likely generated at a comparatively long reconnection line or lines, although the magnetic shear across the magnetopause is not high enough to exclude the "elbowshaped" model entirely.
\end{abstract}

Keywords. Magnetospheric physics (Magnetopause, cusp, and boundary layers; Solar wind-magnetosphere interactions) - Space plasma physics (Magnetic reconnection)

\section{Introduction}

Flux transfer events (FTEs) are the in situ manifestation of time-varying reconnection at the terrestrial magnetopause. Originally observed by Haerendel et al. (1978) and Russell and Elphic $(1978,1979)$, FTEs can be identified by a charac-

Correspondence to: R. C. Fear

(r.fear@ion.le.ac.uk) teristic bipolar signature in the component of the magnetic field normal to the local magnetopause, $B_{N}$ (Russell and Elphic, 1978; Rijnbeek et al., 1982; Rijnbeek and Cowley, 1984). Furthermore, the following features may also be observed (Paschmann et al., 1982):

- deflections in the magnetic field components tangential to the magnetopause;

- plasma signatures of reconnection (acceleration of the local electron and ion population, and field-aligned plasma populations typical of the opposite side of the magnetopause);

- either an enhancement or decrease in the magnetic field strength (an enhancement due to the internal structure of the FTE and the compression of draped magnetic field lines around the FTE core, or a decrease due to the diamagnetic effect as the magnetic pressure drops to compensate for increased thermal pressure within the FTE).

The initial model of FTE structure at the magnetopause, proposed by Russell and Elphic (1978), was of a flux rope of open magnetic flux with an approximately circular crosssection, which crossed through an approximately circular "hole" in the magnetopause. Such a flux tube can only exist on a small region of the magnetopause, but subsequently other models have been proposed which can extend across considerable longitudinal distances such as flux ropes formed by multiple X-line reconnection (Lee and Fu, 1985), or thickening of the magnetopause along a long, single reconnection line (Southwood et al., 1988; Scholer, 1988a). The scale size of an FTE in its direction of motion along the magnetopause $\left(D_{V}\right)$ can be determined from a single-spacecraft observation by multiplying the duration of the signature with an assumed or measured FTE propagation speed. Early measurements estimated $D_{V}$ to be of order 2-4 $R_{E}$ (Russell and Elphic, 1978; Rijnbeek et al., 1984). More recently, multi-spacecraft techniques (Russell et al., 1983; Harvey, 1998) have been

Published by Copernicus Publications on behalf of the European Geosciences Union. 
used to determine FTE velocity more accurately (e.g. Owen et al., 2001, who in a case study estimated $D_{V}$ to be of order $0.8 R_{E}$ ). Fear et al. (2007) calculated the scale size between the positive and negative peaks of the bipolar signature of 142 FTEs which were observed by all four Cluster spacecraft (a similar, but not identical measure to $D_{V}$ ), and found that most FTEs were between 0.6 and $2.2 R_{E}$, although smaller events were under-represented as a consequence of the requirement of the FTE to be observed by all four Cluster spacecraft. An FTE's scale size normal to the magnetopause $\left(D_{N}\right)$ can be estimated either by a suitable conjunction of different spacecraft (e.g. Saunders et al., 1984), or statistically based on the number of FTEs observed per magnetopause crossing (Rijnbeek et al., 1984). These two papers both estimated $D_{N}$ to be the order of $1 R_{E}$.

One key difference between the Russell and Elphic (1978) FTE model and most others is the FTE scale size in the plane of the magnetopause, perpendicular to the direction of motion of the FTE. This azimuthal extent would typically be larger in the models proposed by Lee and Fu (1985), Southwood et al. (1988) and Scholer (1988a) than in the Russell and Elphic (1978) FTE model. However, most previous multi-spacecraft observations of FTEs have either been at separations that were too small to provide useful information on the azimuthal extent, or conjunctions between independent spacecraft which were also at large latitudinal separations, such that different spacecraft observed FTEs with different polarities and therefore observed either independent FTEs or different branches of the same FTE (e.g. Elphic and Southwood, 1987; Wild et al., 2005a; Dunlop et al., 2005; Le et al., 2008). One recent study by Wang et al. (2007) examined a conjunction between the Cluster and Double Star TC-1 satellites which were separated by $3 R_{E}$ in the $Z_{\mathrm{GSM}}$ direction, with the Cluster spacecraft at a separation of $200 \mathrm{~km}$. FTE signatures were observed by TC-1 nearly two minutes after those observed by Cluster; it was postulated that both Cluster and TC- 1 observed the same flux tube at different positions along its length.

Large-scale observations can be made of the ionospheric signatures of magnetopause FTEs; these signatures can take the form of poleward moving features which are observed either optically (poleward moving auroral forms - PMAFs: Sandholt et al., 1986, 1992; Fasel, 1995), as regions of enhanced ionospheric flow observed embedded within intervals of ionospheric radar backscatter (pulsed ionospheric flows PIFs: Pinnock et al., 1993, 1995; Provan et al., 1998; Wild et al., 2007), or as discrete regions of ionospheric radar backscatter with high flows (poleward moving radar auroral forms - PMRAFs: Milan et al., 2000; Wild et al., 2001). Milan et al. (2000) presented coordinated observations of PMAFs (observed in ultra violet) and PMRAFs which extended over $7 \mathrm{~h}$ of magnetic local time. This showed that time-varying reconnection could be active over a large azimuthal extent of the magnetopause (see also theoretical discussion by Lockwood and Davis, 1996), although in the ab- sence of in situ magnetopause observations, the corresponding FTE structure at the magnetopause was not known.

The four-spacecraft Cluster mission has the capability to resolve this issue. Observations at scales between 100 and $5000 \mathrm{~km}$ have enabled the study of FTE motion at the magnetopause (Owen et al., 2001; Wild et al., 2005a; Dunlop et al., 2005; Fear et al., 2005, 2007), FTE structure (Hasegawa et al., 2006; Owen et al., 2008), further study of the statistics of FTE occurrence (Wang et al., 2005, 2006; Fear et al., 2005, 2007) and conjugated magnetopause/ionospheric studies using the SuperDARN radar network (Wild et al., 2001, 2003, 2005b, 2007; Marchaudon et al., 2004; Amm et al., 2005). In this paper we present the first observations of FTEs from the Cluster $10000 \mathrm{~km}$ separation magnetopause crossing season, enabling in situ examination of the scale lengths of an FTE in all three dimensions. The FTEs were observed by the Cluster spacecraft as they crossed the dayside magnetopause on 27 January 2006 at approximately 15:00 h magnetic local time. In the following section, we will examine several of the most commonly cited models of FTE occurrence. In Sect. 3 we shall briefly discuss the instrumentation used and an overview of the interval before a detailed examination of in situ FTE signatures in Sect. 4. The in situ observations reveal that the azimuthal scale size $\left(D_{M}\right)$ of one of the FTEs is larger than its poleward scale size. We show that the FTE is inconsistent with a simple interpretation of the model proposed by Russell and Elphic (1978), but is consistent with being created at a longer X-line or X-lines (Lee and Fu, 1985; Southwood et al., 1988; Scholer, 1988a). However, further observations with larger magnetic shear across the magnetopause are necessary to exclude conclusively the Russell and Elphic (1978) model.

\section{FTE models}

Several models have been proposed to explain the observed spacecraft signatures, which we shall now introduce in detail.

\subsection{Elbow-shaped flux rope model}

The first model, proposed by Russell and Elphic (1978), consisted of two flux ropes which are formed at a spatiallylimited reconnection site in a short burst of reconnection. These flux ropes are therefore narrow in their azimuthal extent, have a roughly circular cross-section and define a bundle of open magnetic flux. They are kinked at the point at which the flux crosses the magnetopause (an approximately circular "hole" in the magnetopause with a diameter of order $1 R_{E}$ ), forming an "elbow" (using the terminology of Scholer, 1995). Away from the reconnection site, the ropes are aligned with the local magnetosheath/magnetospheric magnetic field, and near the reconnection site the rope bends between these two orientations. The flux ropes both move away from the reconnection site as a consequence of the net effect 
(a)

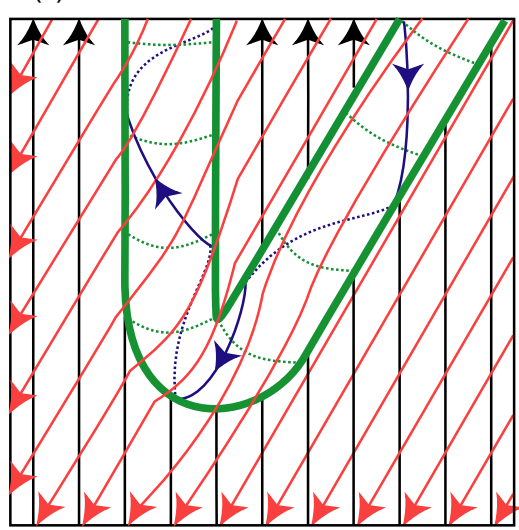

(b) (c)

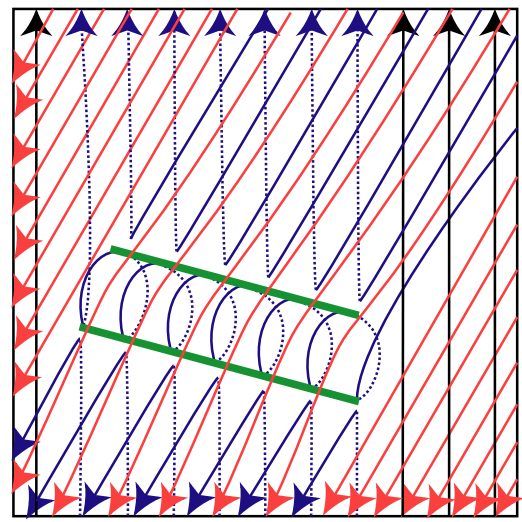

(d)

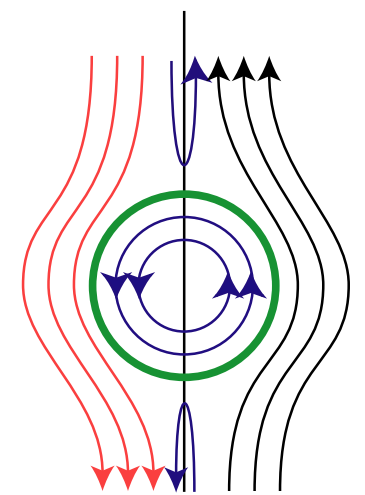

(e)

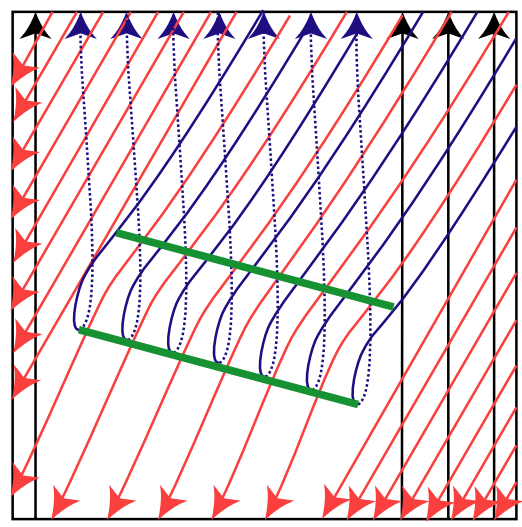

(f)

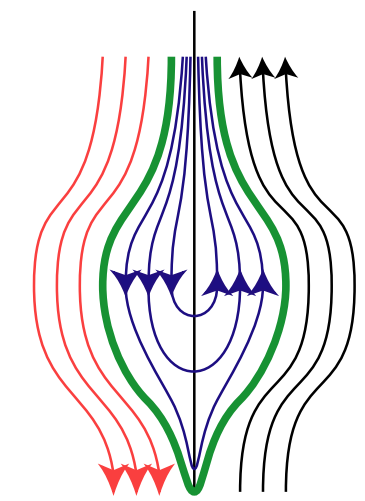

Fig. 1. Three different FTE models, sketched for a magnetosheath magnetic field clock angle of $150^{\circ}$. The sketches show: (a and b) the Russell and Elphic $(1978,1979)$ flux tube model, including the internal helical magnetic field explained by Sonnerup (1987); (c and d) the multiple X-line model suggested by Lee and Fu (1985) and (e and f) the bursty reconnection single X-line model developed independently by Scholer (1988a) and Southwood et al. (1988). Black and red lines represent unreconnected magnetospheric and magnetosheath magnetic field lines respectively; blue lines represent reconnected magnetic field lines. The edge of the FTE is marked in green. The top row shows views along an axis normal to the magnetopause surface, and the bottom row shows views tangential to the magnetopause.

of magnetic tension (the $\boldsymbol{j} \times \boldsymbol{B}$ force exerted by the magnetopause current on the flux in the flux rope which threads through the hole in the magnetopause) and the force exerted by the magnetosheath flow. Unreconnected magnetic field drapes around the flux ropes, providing a bipolar $B_{N}$ signature if the spacecraft observes these draped field lines. Cowley (1982) and Paschmann et al. (1982) noted that the magnetic field lines within the flux ropes must form a helix, otherwise there would be no normal component of the magnetic field within the flux rope itself (the FTE "core"), and hence no bipolar $B_{N}$ signature in the core. This helical field was explained theoretically by Sonnerup (1987) as a consequence of the deflection of unreconnected magnetic flux around the hole in the magnetopause as the FTE propagates. The gathering-up of such flux causes a difference in the flux density on one side of the hole compared with the other, and therefore a current is formed as a result of Ampère's Law.

A sketch of the elbow-shaped flux rope model is shown in Fig. 1a and b. In this figure, the background magne- tospheric magnetic field is taken to be directed upward in all panels. Panels in the top row show a view of the magnetopause plane (i.e. along an axis normal to the magnetopause), whilst the bottom row panels show a view along the magnetopause plane. The unreconnected magnetosheath magnetic field is sketched with an orientation of $150^{\circ}$ to the magnetospheric magnetic field. Black and red arrowed lines represent unreconnected magnetospheric and magnetosheath magnetic field lines respectively; blue lines represent reconnected magnetic field lines (dotted blue lines are behind the plane of the sketch). The green lines mark the edge of the FTE. One FTE is shown in Fig. 1a and b, a short time after it has been formed. This FTE is connected to the Northern Hemisphere; the corresponding FTE connected to the Southern Hemisphere would be below the figure.

An important feature of the elbow-shaped flux rope model is that the flux ropes are narrow in their extent perpendicular to the local unreconnected magnetic field, since the flux tubes are generated at a short reconnection site (of order $1 R_{E}$ ). 
Consequently, the flux tubes will not extend far in the azimuthal direction (horizontally in Fig. 1a) when the magnetosheath magnetic field is nearly antiparallel to the magnetospheric magnetic field.

\subsection{Multiple X-line model}

Subsequently, other reconnection-based models were proposed to explain the observed signatures. Lee and $\mathrm{Fu}$ (1985) suggested that flux tubes could be formed between multiple reconnection lines (X-lines). This multiple $\mathrm{X}$-line model is sketched for the simplest case of two X-lines in Fig. 1c and d. An identical magnetosheath magnetic field orientation to that in the earlier panels is assumed. In this case, the green lines in panel (c) not only mark the edge of the FTE, but (if the sketch is taken to be at the time of reconnection) they also represent the two X-lines. As there is an azimuthal component in the magnetosheath magnetic field, the magnetosheath and magnetic field lines between the X-lines form a flux tube with a helical magnetic field. Reconnected (open) magnetic field lines are observed outside the flux tube structure; consequently in these regions "steady-state" reconnection signatures should be observed (i.e. plasma reconnection signatures and a non-zero $B_{N}$ component), but no bipolar $B_{N}$ signature will be observed until the flux tube passes. The scenario sketched in Fig. 1 can be generalised; if $n$ X-lines are formed, $(n-1)$ flux tubes (FTEs) will be formed.

There are four key differences between the elbow-shaped flux rope model and the multiple X-line model. First, the flux rope created in the multiple $\mathrm{X}$-line model can become extended azimuthally along the magnetopause, since there is no constraint within the model on the length of the X-lines that formed it. Conversely, reconnection in the elbow-shaped flux tube model is spatially patchy; if a coherent flux tube is formed along a long reconnection line, the flux tube ceases to have a roughly circular cross-section, the internal field ceases to be helical and a direct entry onto open magnetic field lines will not yield a bipolar $B_{N}$ signature. Second, in the elbow-shaped flux tube model all of the reconnected flux maps from the magnetosheath to the ionosphere through the flux tube, whereas in the multiple X-line model only a small proportion of the open magnetosheath magnetic field lines map through the FTE; in the sketch in Fig. 1c, only one field line does so (the leftmost solid blue line, which is connected via the flux tube to the rightmost dotted blue line). Most of the ionospheric signature will be due to the majority of the open magnetic field lines which (due to being above the top $\mathrm{X}$-line or below the bottom X-line) are not part of the FTE structure. Third, the plasma signatures may differ: in the multiple X-line model, there are open magnetic field lines outside the flux rope (i.e. either side of the bipolar $B_{N}$ signature). If a spacecraft observes the open field lines that are outside the flux rope, then plasma reconnection signatures would be observed outside the FTE itself, unless the multiple $\mathrm{X}$-line model is combined with the single $\mathrm{X}$-line model outlined in the following section. Fourth, the elbow-shaped flux tube model always produces an even number of FTEs, since the FTEs are generated in pairs. In the multiple Xline model, the number of FTEs generated depends upon the number of X-lines, and so can be even or odd.

\subsection{Single X-line model}

A third model was proposed independently by Southwood et al. (1988) and Scholer (1988a). This model is based on bursty reconnection at a single X-line, and is sketched for the same magnetosheath orientation in Fig. 1e and f. In both sketches, a green line denotes the edge of the FTE; if the FTE had been sketched at the instant of reconnection, then the bottom green line in panel (e) would represent an X-line.

In this single $\mathrm{X}$-line model, reconnection may or may not be occurring before the creation of the FTE; however if there is an increase in the rate of reconnection, the angle between the reconnected field line and the local magnetopause surface (the opening angle) will increase (Owen and Cowley, 1987). Southwood et al. (1988) argue that ahead of this point, the heating of plasma by the reconnection process causes the thermal pressure to increase, forming a bulge in the magnetopause boundary layer. As the reconnection rate decreases the opening angle decreases, although it remains positive (Owen and Cowley, 1987). This decrease is seen at the very bottom of the structure in Fig. 1f. Therefore, if the reconnection rate suddenly increases and then decreases, a bulge or "bubble" is formed. As this structure propagates, the internal FTE "core" of reconnected field lines and the draping around this structure cause the bipolar $B_{N}$ signature. As noted by Southwood et al. (1988), an internal magnetic field component along the structure can be added by the influence of either a magnetic field shear (i.e. not strictly antiparallel magnetic fields), or a flow shear. Scholer (1988b) developed this model to explain the strong enhancement in the magnetic field strength that is often observed in the FTE core.

The single X-line model has some similarities with the multiple X-line model. Both are able to extend an arbitrary length along the magnetopause, and may therefore extend for large azimuthal distances in comparison with the elbowshaped flux rope model. Both are therefore able to reconnect large quantities of flux in coherent structures. In both cases, it is the limited poleward extent of the structure which provides the bipolar $B_{N}$ signature, whereas it is the finite width of the flux rope in the elbow-shaped flux rope model which does so. However, all magnetic flux reconnected within the single X-line model forms part of the FTE. As is the case with the elbow-shaped flux tube model, an even number of FTEs are always created in the single X-line model.

\subsection{Other models}

Each of the above models is based on the process of magnetic reconnection. The discussion above has focused on the 
FTE structure and the observed magnetic signature, but in each case, passage of a spacecraft onto open magnetic field lines within the FTE will result in the observation of plasma reconnection signatures (an exchange of plasma across the magnetopause, and acceleration of the local plasma population).

However, other models have also been proposed. Sibeck $(1990,1992)$ suggested that magnetopause waves could generate FTE-like signatures without invoking magnetic reconnection. Sibeck proposed that the bipolar signature could be caused by an indentation in the magnetopause, caused by a pressure pulse, which is outrun by a fast-mode wave within the magnetosphere which results in an outward expansion of the magnetopause due to an increase in the magnetic pressure. Sibeck (1990) suggested that the plasma signatures could be explained by the passage of the spacecraft across the low latitude boundary layer and the plasma depletion layer as the wave passes. However, Smith and Owen (1992) examined the ion velocity distribution within an event previously discussed as both an FTE (Rijnbeek et al., 1987; Farrugia et al., 1988) and pressure-pulse driven magnetopause crossing (Sibeck, 1992), and observed a variation in the temperature anisotropy that was inconsistent with the Sibeck (1990) model unless reconnection was occurring simultaneously.

Finally, it has been suggested that impulsive plasma penetration may occur when a plasma element in the solar wind has a larger momentum density than the surrounding plasma, and that this process may give rise to signatures attributed to FTEs (Lemaire and Roth, 1978; Lemaire et al., 1979; Heikkila, 1982). However, Smith and Curran (1990) showed that there was a poorer correlation between FTE occurrence and the "magnetopause penetration parameter" defined by Lemaire et al. (1979) than the correlation with IMF, and Owen and Cowley (1991) argued that the mechanism proposed by Heikkila (1982) was theoretically invalid.

\section{Instrumentation and data overview}

In this paper, we present in situ data from the Cluster Fluxgate Magnetometer instruments (FGM, Balogh et al., 2001) at both $4 \mathrm{~s}$ and $5 \mathrm{~Hz}$ resolution. Electron pitch angle distribution data from the Cluster PEACE electron spectrometers (Johnstone et al., 1997; Owen et al., 2001) are also used. PEACE data are presented at spacecraft spin resolution $(\sim 4 \mathrm{~s})$.

Solar wind conditions are provided by the MGF magnetometer (Kokubun et al., 1994) and Comprehensive Plasma Instrumention (CPI, Frank et al., 1994) onboard Geotail, which was situated in the solar wind on the dawn flank of the Earth at $(3.7,-27.0,-10.6)_{\mathrm{GSM}} R_{E}$.

The locations of the Cluster spacecraft at 19:30 UT on the 27 January 2006 are shown in Fig. 2. The Cluster tetrahedron was located near the dayside magnetopause at about 15:00 h magnetic local time as the spacecraft moved from the mag-
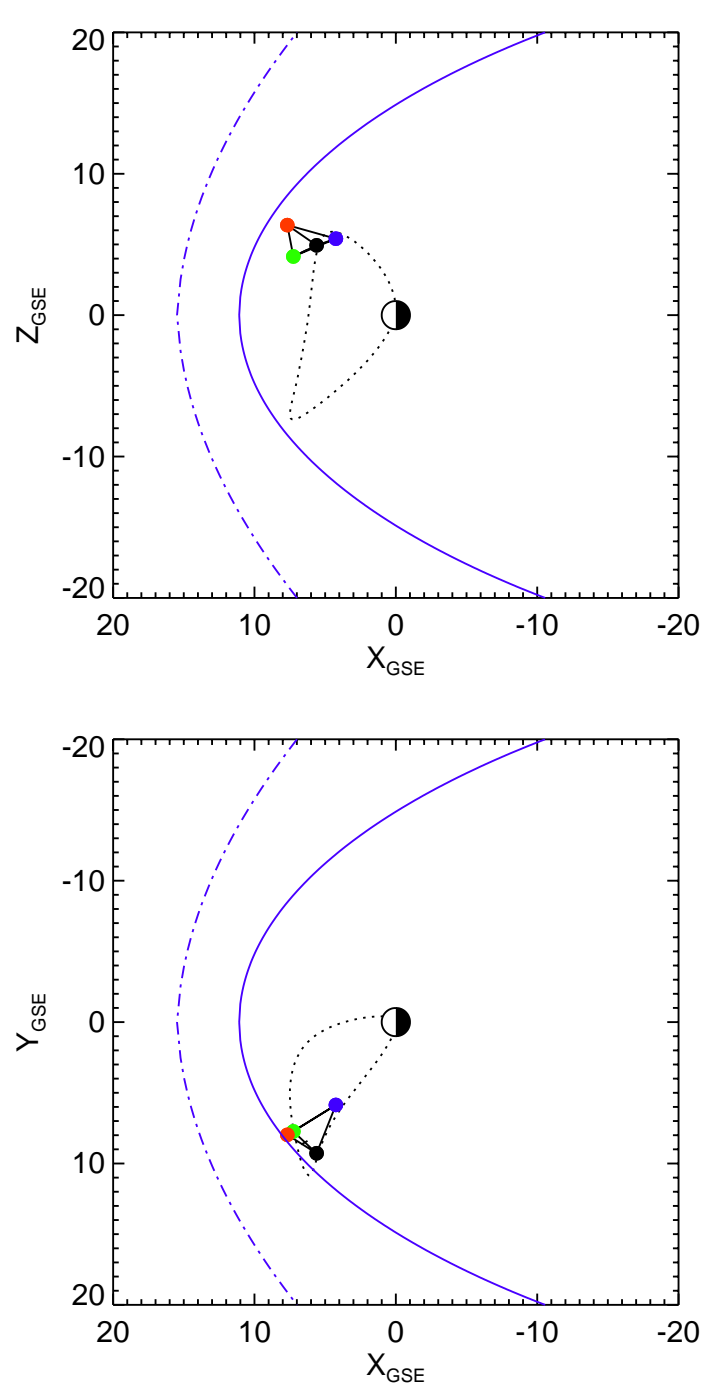

Fig. 2. The location of the Cluster spacecraft in the GSE XZ (top) and XY (bottom) planes at 19:30 UT on the 27 January 2006. The location of Cluster 1 is represented by a black dot; the positions of the other three spacecraft are expanded by a factor of two with respect to Cluster 1. Clusters 2, 3 and 4 are represented by red, green and blue dots. A model bow shock and magnetopause are shown as blue dot-dash and solid lines respectively (Tsyganenko, 1995; Peredo et al., 1995). The dotted black line shows a field line from the Tsyganenko (1995) model which is traced through the location of Cluster 1. The Cluster orbit crossed the magnetopause at about 15:00 h magnetic local time. Clusters 1, 2 and 3 were all relatively close to the model magnetopause, whilst Cluster 4 was situated deeper into the magnetosphere.

netosphere into the magnetosheath. In this figure, the Cluster tetrahedron is expanded by a factor of two. Clusters 1,2 and 3 were all located comparatively close to the nominal magnetopause, whilst Cluster 4 was situated deeper into the magnetosphere. 


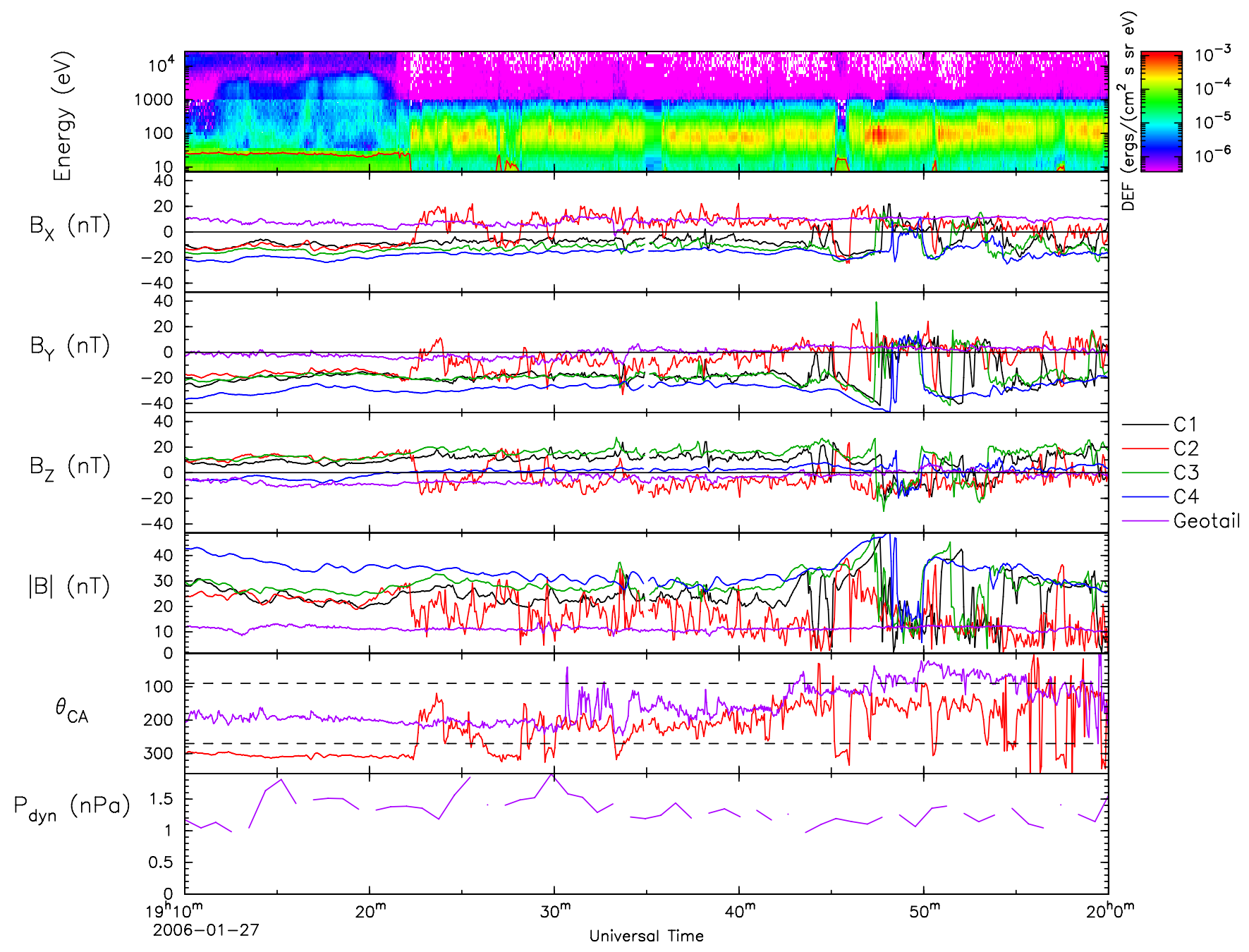

Fig. 3. An overview of the Cluster observations. From top: an omnidirectional PEACE spectrogram from Cluster 2; the magnetic fields measured by the Cluster FGM and Geotail MGF instruments in GSM coordinates; the clock angle $\left(\theta_{C A}=\arctan \left[B_{Y} / B_{Z}\right]\right)$ of the IMF observed by Geotail (purple line) and the magnetospheric/magnetosheath magnetic field observed by Cluster 2 (red line), and the solar wind dynamic pressure observed by the Geotail CPI instrument. The IMF has been multiplied by a factor of four to enable comparison with the magnetosheath magnetic field.

An overview of the observations is shown in Fig. 3. The top panel shows an omnidirectional spectrogram of the electron differential energy flux observed by the PEACE instrument onboard Cluster 2. Prior to 19:22 UT, Cluster 2 was in the magnetosphere, as evidenced by the hot, rare electron distribution. At 19:22 UT, Cluster 2 entered the magnetosheath, which is shown by the observation of a cooler, denser electron population. The magnetosheath population was observed by Cluster 2 until after 20:00 UT, although there were brief entries back into the magnetosphere throughout this time.

The next four panels of Fig. 3 show the magnetic field observed by all four Cluster spacecraft, in the same colour scheme as used in Fig. 2 (and which shall be used throughout this paper). In this figure, the magnetic field is shown at $4 \mathrm{~s}$ resolution. Before 19:22 UT, Clusters 1, 2 and 3 observed an antisunward, dawnward and northward magnetic field, consistent with their location in the northern/post-noon quadrant of the dayside magnetosphere. Cluster 4 observed a similar magnetic field from 19:20 UT onwards, but with a weaker $B_{Z}$ component. At 19:22 UT, as indicated by the PEACE measurements, Cluster 2 entered the magnetosheath, and a rotation in the magnetic field was observed by this spacecraft. As can be seen by comparing the magnetic fields observed by the four spacecraft (particularly the $B_{X}$ component), Clusters 1 , 3 and 4 remained in the magnetosphere until a brief entry into the magnetosheath at 19:47 UT. Overlaid on these four panels is the interplanetary magnetic field (IMF) observed by 

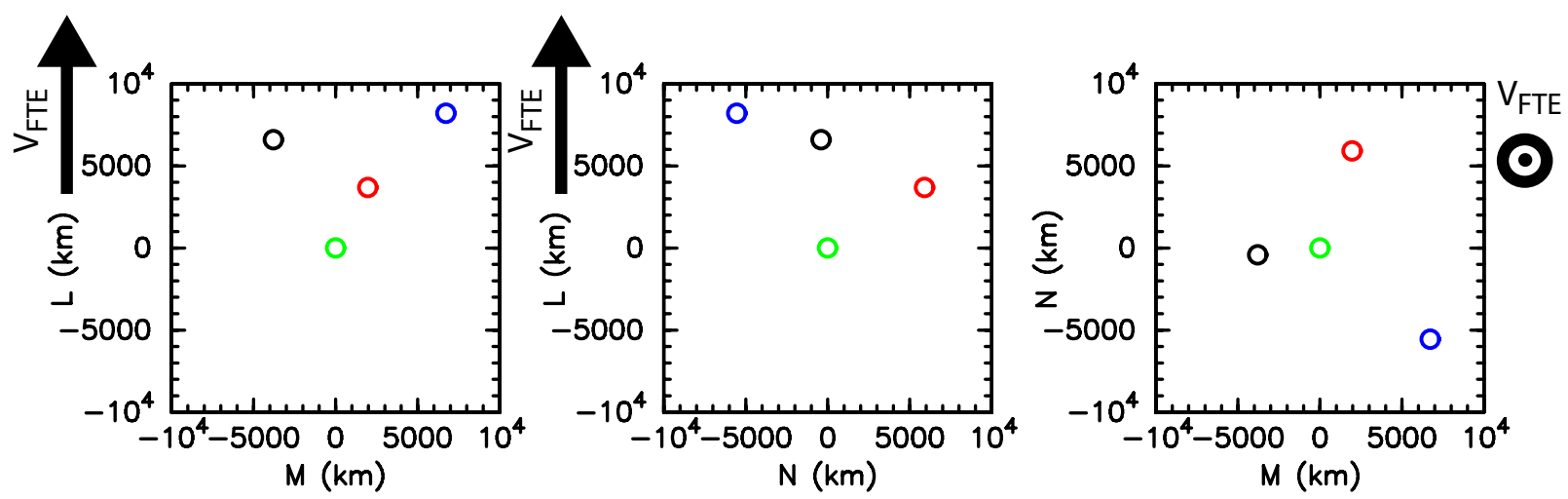

Fig. 4. The orientation of the Cluster spacecraft at 19:30 UT in boundary normal coordinates. The panels indicate, from left, the LM, LN and MN planes. Each spacecraft is represented by a circle, using the same colour code as used in Fig. 2. The velocity of the FTE discussed in Sect. 4.4 is indicated beside each panel.

the Geotail MGF instrument. To ease comparison with the magnetic fields observed by Cluster, the IMF has been multiplied by an arbitrary factor of 4 . Throughout the interval, the IMF was largely directed sunward, but also had weak $B_{Y}$ and $B_{Z}$ components. Between 19:20 and 19:50 UT, the IMF $B_{Z}$ component was consistently negative, and about $-0.5 \mathrm{nT}$.

The penultimate panel of Fig. 3 compares the clock angle of the IMF observed by Geotail with the clock angle observed by Cluster 2 (which was situated in the magnetosheath for most of the interval). Between 19:20 and 19:50 UT, the IMF and magnetosheath clock angles both rotated from southward and dawnward to duskward, although the radial component of the IMF predominated throughout. The bottom panel shows the solar wind dynamic pressure observed by the Geotail CPI instrument, which exhibited three enhancements before 19:30 UT, and then remained steady for the rest of the interval. We note, though, that a compression of the magnetosphere was observed by Cluster leading to an exit into the magnetosheath at 19:48 UT without any corresponding increase in the solar wind dynamic pressure; therefore it may be that the Geotail plasma observations do not accurately reflect the situation that would be observed immediately upstream of the Earth.

\section{In situ FTE observations}

In order to examine the Cluster magnetometer data for FTE signatures, a boundary normal coordinate system (Russell and Elphic, 1978) was derived, in which $\hat{\boldsymbol{n}}$ is normal to the average local magnetopause surface, $\hat{l}$ is the projection of the Earth's magnetic dipole (the solar-magnetic $\hat{z}$ axis) onto the plane defined by $\hat{\boldsymbol{n}}$, and $\hat{\boldsymbol{m}}$ is directed azimuthally to complete the right-handed set $(\hat{\boldsymbol{l}}-\hat{\boldsymbol{m}}-\hat{\boldsymbol{n}})$.

Minimum variance analysis (Sonnerup and Cahill, 1967; Sonnerup and Scheible, 1998) was carried out on the mag- netic field observed by Cluster 2 at $5 \mathrm{~Hz}$ resolution between 19:10 and 20:00 UT. This interval contained not only the main magnetopause crossing at 19:20 UT, but also several briefer excursions back into the magnetosphere. The minimum variance eigenvector was taken to be the magnetopause normal $\hat{\boldsymbol{n}}=(0.677,0.294,0.675)_{\mathrm{GSE}}$. This normal is reasonably well defined with an intermediate/minimum eigenvalue ratio of 3.2. The normal vector is approximately $24^{\circ}$ from the normal vectors derived from the Roelof and Sibeck (1993) and Shue et al. (1998) models, but it is very close to perpendicular to the magnetosheath magnetic field observed by Cluster 2 outside the FTEs $\left(96^{\circ}\right)$ and to the magnetosheath velocity observed by Cluster 1 after it crossed the magnetopause at 19:48 UT $\left(90.3^{\circ}\right)$. The azimuthal vector $\hat{\boldsymbol{m}}=(0.031,-0.927,0.373)_{\mathrm{GSE}}$ was defined by normalising $\hat{\boldsymbol{n}} \times \hat{\boldsymbol{z}}_{S M}$, and $\hat{\boldsymbol{l}}=(-0.735,0.232,0.637)_{\mathrm{GSE}}$ was calculated by taking the cross product $\hat{\boldsymbol{m}} \times \hat{\boldsymbol{n}}$.

The orientation of the Cluster tetrahedron is shown in boundary normal coordinates in Fig. 4. This figure shows that the tetrahedron extended more than $10000 \mathrm{~km}$ in the $\mathrm{N}$ and $\mathrm{M}$ directions (normal to the magnetopause and azimuthally along the magnetopause), and just under $10000 \mathrm{~km}$ in the L direction (poleward along the magnetopause).

The magnetic field observed by Cluster between 19:20 and 19:50 UT has been plotted in the boundary normal coordinate system in the top four panels of Fig. 5. The middle three panels show electron spectrograms from the PEACE instrument onboard Cluster 2 in three look directions: (from top) parallel, perpendicular and antiparallel to the magnetic field. The pitch angle distributions have been rebinned to the high-resolution magnetic field on the ground, to improve binning accuracy. This results in some data gaps. The bottom three panels show equivalent spectrograms from the PEACE instrument on Cluster 3, but since the magnetic field observed by Cluster 3 is more stable than that observed by 


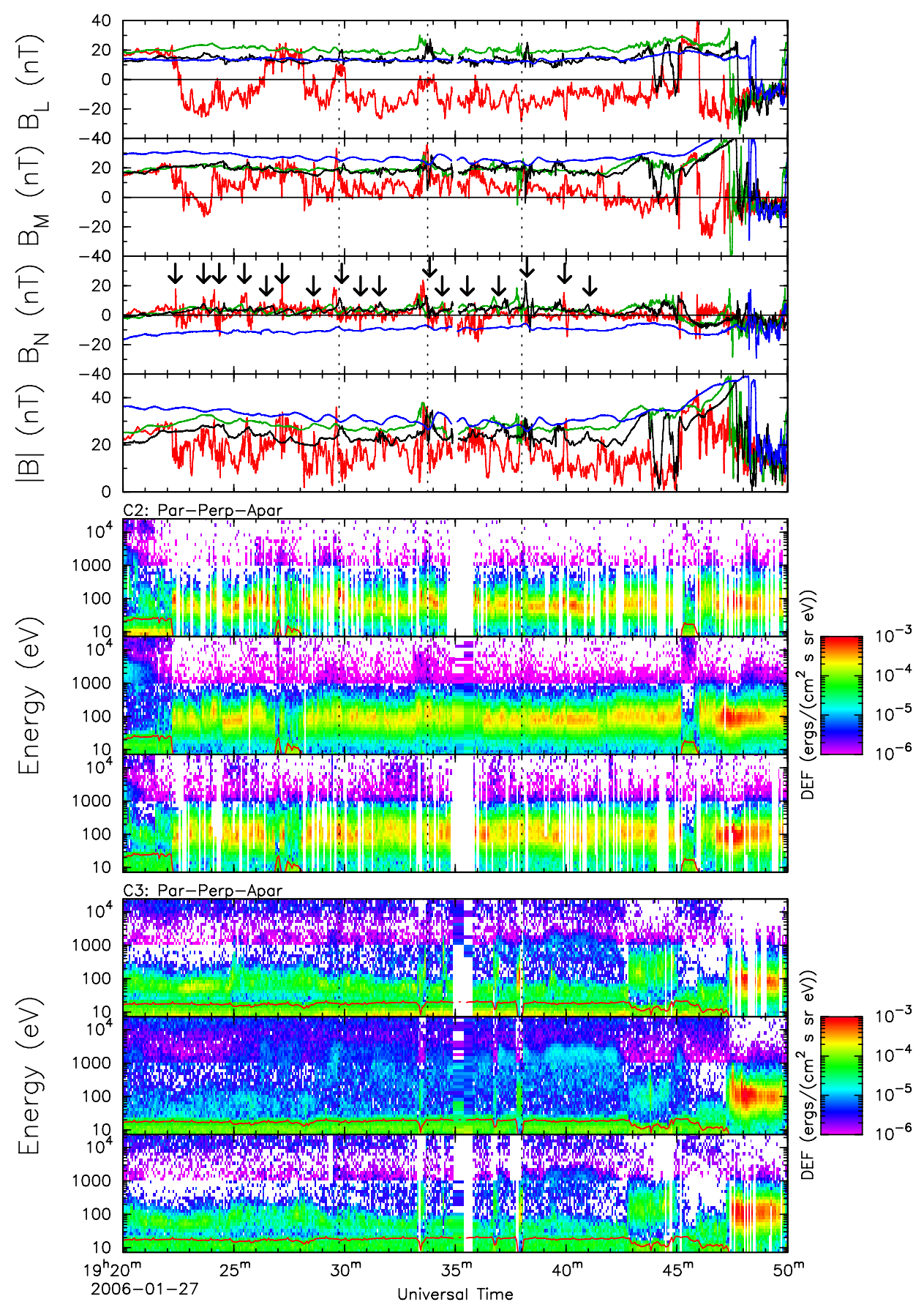

Fig. 5. FTE signatures observed by Cluster. The top four panels show the magnetic field observed by the four Cluster spacecraft in boundary normal coordinates. Many bipolar $B_{N}$ signatures are evident in the data from Cluster 2 (red trace), whilst Cluster 2 was in the magnetosheath (as evidenced by a negative $B_{L}$ component). Several of these signatures are also observed by Clusters 1 and 3 (black and green), and three FTEs also have weak counterparts which are observed at Cluster 4 (blue trace). Arrows indicate FTEs observed by at least one spacecraft, and vertical dotted lines indicate FTEs which were observed by all four spacecraft. The middle three panels show electron spectrograms from the PEACE instrument onboard Cluster 2. They show the differential energy flux of electrons moving parallel/perpendicular/antiparallel to the magnetic field. The spacecraft potential is indicated by a red line; electrons at energies below this trace are due to photoionisation of the spacecraft, and do not form part of the natural plasma environment. Accelerated magnetosheath-energy electrons are observed which coincide with the FTE signatures. The bottom three panels follow the same format, but show PEACE data from Cluster 3, which was situated in the magnetosphere. Several transient, field-aligned bursts of magnetosheath energy electrons are observed. 
Cluster 2, there are fewer data gaps. The intervals during which Cluster 2 was in the magnetosheath can be identified by the presence of an omnidirectional, low energy, high density electron population and a negative $B_{L}$ component. Cluster 2 first crossed the magnetopause at 19:22 UT, after which it remained in the magnetosheath for most of the time, although some brief entries into the magnetosphere were observed (most notably at 19:27 and 19:45 UT). Clusters 1, 3 and 4 remained in the magnetosphere until after 19:47 UT.

In this interval, 17 bipolar signatures were observed in the Cluster $2 B_{N}$ trace, which we identify as FTEs and indicate with arrows in Fig. 5. Three FTEs (observed at 19:30, 19:34 and 19:38 UT and indicated by dotted lines in Fig. 5) were associated with a signature on all four spacecraft, although the signatures observed by Cluster 4 were weak and offset with respect to $B_{N}=0$. We now examine these three FTEs in more detail.

\subsection{First FTE - 19:30 UT}

An enlargement of the magnetic field and electron signatures observed by Cluster at 19:30 UT is shown in Fig. 6. The first four panels show the magnetic field observed by all four spacecraft in boundary normal coordinates. Cluster 2, located in the magnetosheath, observed the largest bipolar signature and magnitude enhancement. Clusters 1 and 3, which were situated in the magnetosphere, also observed a clear bipolar $B_{N}$ signature; Cluster 1 also observed a clear enhancement in $|\boldsymbol{B}|$. Cluster 4, which was also in the magnetosphere but further away from the magnetopause, observed only a slight variation in the $B_{N}$ trace, which is not clearly bipolar.

The remaining panels show spectrograms of the electron distributions parallel and antiparallel to the magnetic field, observed by Clusters 2, 3 and 1. The spacecraft are presented in position order, working initially inward from the magnetosheath to the magnetosphere, and then poleward. As in Fig. 5, the electron data have been rebinned to pitch angles on the ground. This procedure provides more accurate pitch angle information, but does result in some data gaps (particularly in the parallel and antiparallel directions) when the magnetic field changes rapidly. However, it can be seen that the energy of the cool, dense, magnetosheath electron population observed by Cluster 2 was briefly enhanced parallel to the magnetic field at 19:29:45 UT, which coincides with the second half of the Cluster $2 B_{N}$ signature. This enhancement was not observed antiparallel to the magnetic field, and is indicative of the spacecraft passing onto open magnetic field lines in the magnetosheath that are connected to the Southern Hemisphere ionosphere. The polarity of the $B_{N}$ signature (positive/negative) indicates that the FTE was moving northward (Rijnbeek et al., 1982). Since it was observed in the Northern Hemisphere the force exerted on the FTE by the magnetosheath flow must have outweighed the magnetic tension force on the kinked magnetic field lines.

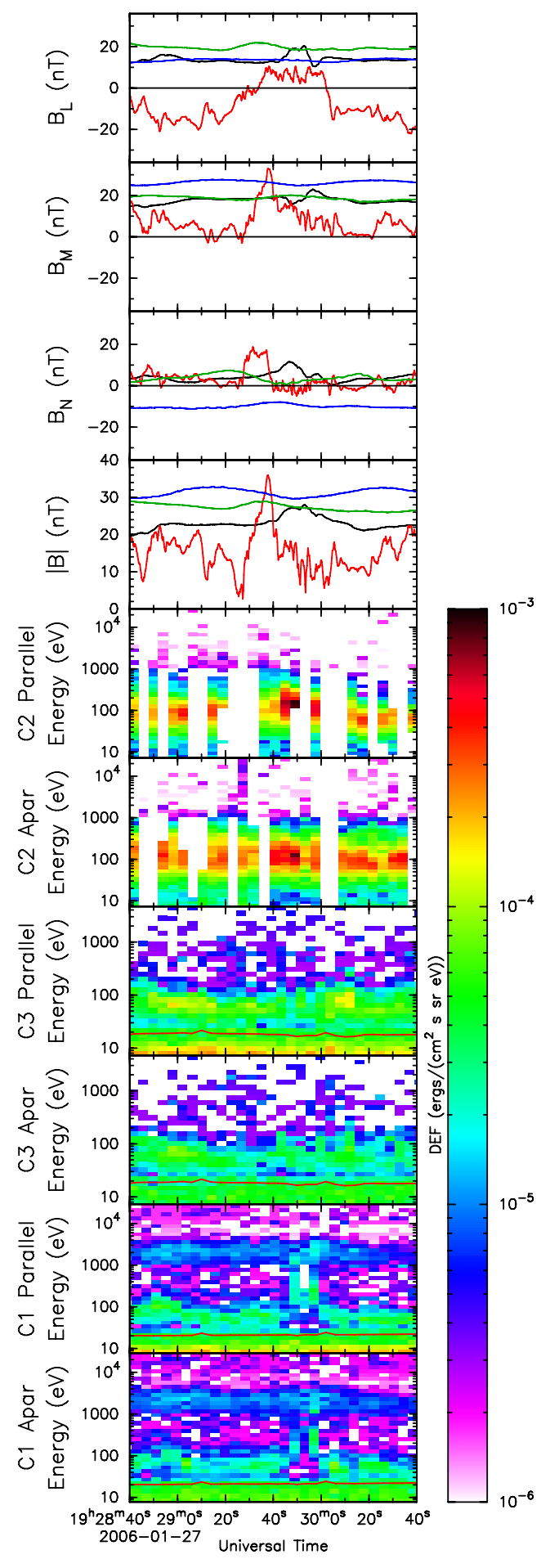

Fig. 6. An enlargement of the FTE signatures observed by the four Cluster spacecraft at 19:30 UT. The panels show (from top), the magnetic field signatures (in boundary normal coordinates) observed by all four spacecraft, and then the parallel and antiparallel electron pitch angle distributions observed by Clusters 2, 3 and 1. The red line in the spectrograms shows the spacecraft potential. 


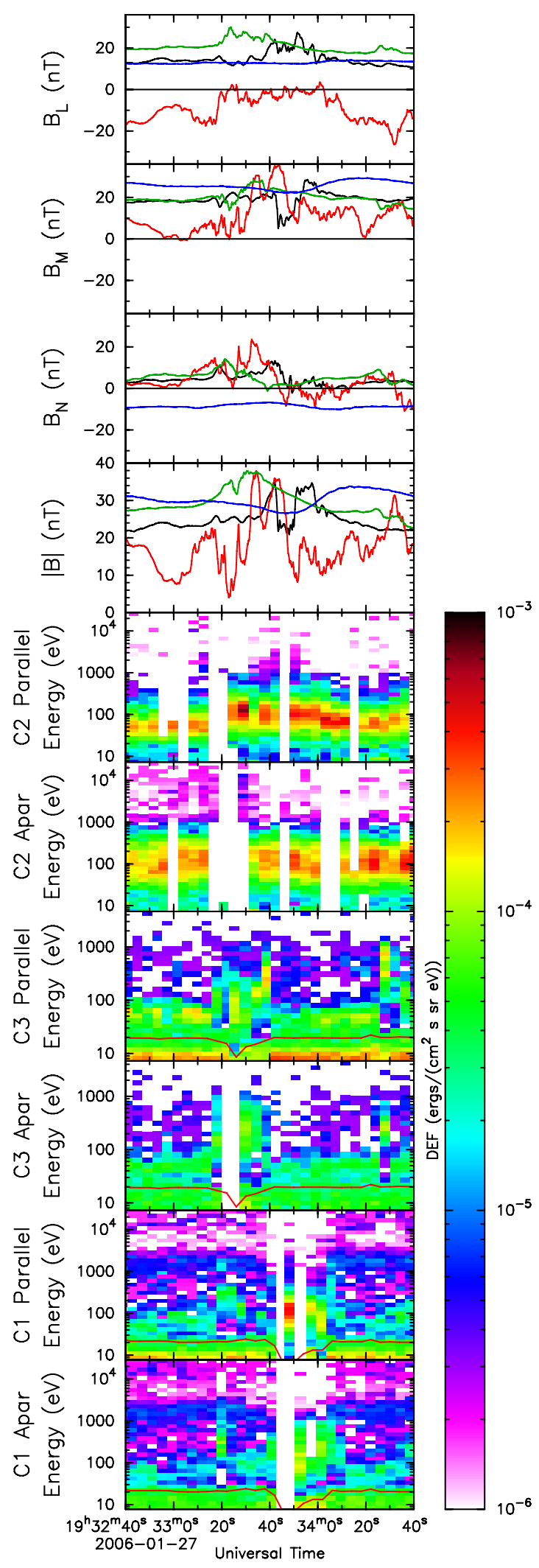

Fig. 7. An enlargement of the FTE signatures observed by the four Cluster spacecraft at 19:33 UT, taking the same format as Fig. 6.
Such instances are not uncommon (Daly et al., 1984; Fear et al., 2007). For such a situation to occur, the magnetosheath flow at the reconnection site must be super-Alfvénic, which has the further consequence that reconnection there must be non-steady (Cowley and Owen, 1989).

In the magnetosphere, there is no evidence of a change in the electron population observed by Clusters 3 or 4 (Cluster 4 not shown), so we conclude that these two spacecraft only observed the draping of magnetic flux around the FTE. However, immediately before the FTE, Cluster 1 observed two populations at energies above the spacecraft potential: a low-energy population $(\sim 100 \mathrm{eV})$ and a higher energy population above $1 \mathrm{keV}$. At 19:29:50 UT, there was a drop-out of the lower energy population and an intermediate population was observed (between $100 \mathrm{eV}$ and $1 \mathrm{keV}$ ). The intermediate population corresponds approximately to the energy of magnetosheath electron plasma, although the differential energy flux is considerably lower than in the magnetosheath. It occurred at the same time as the $|\boldsymbol{B}|$ enhancement was observed. We therefore suggest that the intermediate population could be injected magnetosheath plasma, and that Cluster 1 may have entered onto open magnetic field lines, although there was no significant change to the $1 \mathrm{keV}$ population.

\subsection{Second FTE - 19:33 UT}

The second of the three FTEs observed by all four spacecraft occurred at 19:33 UT and is shown in Fig. 7, which takes the same format as Fig. 6. Again, Cluster 2 (in the magnetosheath) observed the largest $B_{N}$ and $|\boldsymbol{B}|$ variations. The $B_{N}$ signatures observed by Clusters 3 and 1 were more pronounced than at 19:30 UT. Cluster 1 observed a "crater" signature in the magnetic field magnitude (LaBelle et al., 1987; Owen et al., 2008), which is a local minimum within the $|\boldsymbol{B}|$ enhancement, and Cluster 3 observed a brief minimum in $|\boldsymbol{B}|$ within an overall enhancement. Cluster 4 observed a small, but identifiable bipolar signature in $B_{N}$ relative to its background level of $-10 \mathrm{nT}$.

Cluster 2 observed a clearer and longer-lasting energization of the magnetosheath electron plasma parallel to the magnetic field than was observed at 19:30 UT, and no discernable change was observed in the antiparallel pitch angle bin, indicating that this FTE was also connected to the Southern Hemisphere. Clusters 1 and 3 both observed an injection of magnetosheath-energy plasma which coincided with the enhancement in $|\boldsymbol{B}|$. The magnetosheath-energy populations observed by Clusters 1 and 3 are consistent with injection of magnetosheath plasma onto magnetospheric magnetic field lines which have been opened by reconnection. The injected plasma mirrors at low altitudes, causing a bidirectional population to be observed. Therefore, Clusters 1, 2 and 3 all entered onto open magnetic field lines during the passage of this FTE. Cluster 4 did not observe any change in the electron 
population during this FTE, and therefore observed only the draping region as before.

\subsection{Third FTE - 19:38 UT}

The clearest FTE $B_{N}$ signature observed by Cluster 4 occurred at 19:38 UT (Fig. 8). This time, Clusters 1 and 3 (located in the magnetosphere) observed the largest $B_{N}$ deflections, and so we conclude that they were closer to the magnetopause than Cluster 2 was. Cluster 4 observed a clearer bipolar $B_{N}$ signature than at 19:33 UT, although it was again small, and offset with respect to $B_{N}=0$. Clusters 1 and 3 again observed a "crater" signature in the magnetic field magnitude, Cluster 2 observed a straightforward enhancement, and Cluster 4 observed no $|\boldsymbol{B}|$ signature at all. In the magnetosheath, Cluster 2 observed a similar enhancement to that seen in the other two FTEs in the energy of the electron population parallel to the magnetic field. The energy enhancement occurred between 19:38:02 and 19:38:19 UT; this time it was accompanied by a decrease in the differential energy flux. Unfortunately, due to the ground pitchangle binning process, there was a data gap at 19:38:10 UT, but there was no significant difference in the antiparallel electron population observed by Cluster 2 immediately either side of 19:38 UT. In the magnetosphere, a bidirectional electron population of magnetosheath energy $(\sim 100 \mathrm{eV})$ was observed by Cluster 3 between 19:37:47 and 19:38:05 UT. A similar population was observed by Cluster 1 between 19:38:07 and 19:38:36 UT. The electron signatures observed by these two spacecraft coincide with the central depressed region of the crater signature in $|\boldsymbol{B}|$. Once again, there was no electron signature observed at Cluster 4.

\subsection{FTE velocity}

Since a discernable $B_{N}$ signature was observed by all four spacecraft at 19:33 and 19:38 UT, the velocity of these two FTEs can be determined using multi-spacecraft timing analysis (Russell et al., 1983; Harvey, 1998). We consider the $B_{N}$ signature observed by Cluster 4 at 19:30 UT to be too weak to attempt this analysis.

We determined the time difference between the $B_{N}$ signatures being observed by both spacecraft in each of the six possible spacecraft pairs during the 19:33 and 19:38 UT FTEs. This was done by finding the time delay which maximised the cross-correlation between each pair of $B_{N}$ time series, and then adjusting the lag by eye if necessary to achieve the best alignment of three key points: the midpoint of the bipolar $B_{N}$ signature and the positive and negative peaks. These time differences are given in Table 1 , along with the uncertainties on each timing measurement, within which all three key points are aligned, as described by Fear et al. (2007). Using the procedure described by Harvey $(1998$, p. 311), the velocity of the FTE at 19:33 UT was found to be $(399,97,16)_{\mathrm{LMN}} \mathrm{km} \mathrm{s}^{-1}$, and the velocity of the

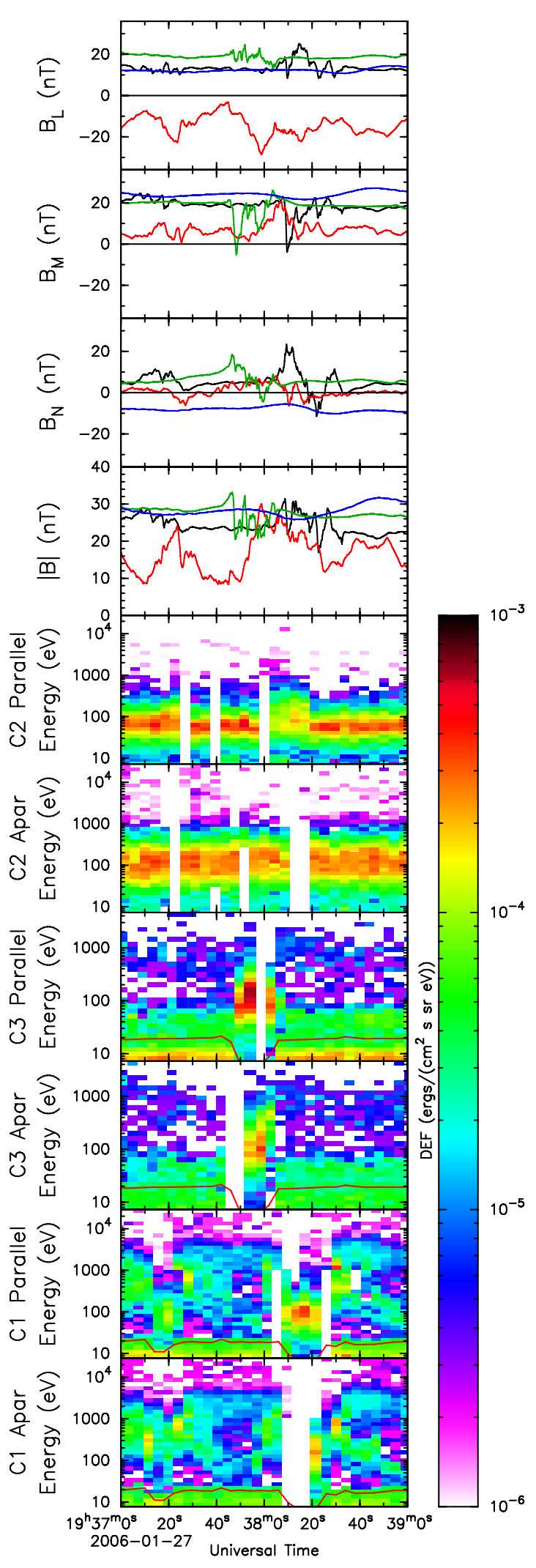

Fig. 8. An enlargement of the FTE signatures observed by the four Cluster spacecraft at 19:38 UT, taking the same format as Fig. 6. 
Table 1. Inter-spacecraft delays determined for the $B_{N}$ signature observed by Cluster at 19:33 and 19:38 UT.

\begin{tabular}{ccc}
\hline & $19: 33 \mathrm{UT}$ & $19: 38 \mathrm{UT}$ \\
\hline$d t_{21}$ & $-2.2 \mathrm{~s} \pm 8.8 \mathrm{~s}$ & $-7.8 \mathrm{~s} \pm 3.2 \mathrm{~s}$ \\
$d t_{31}$ & $-14.0 \mathrm{~s} \pm 5.8 \mathrm{~s}$ & $-23.40 \mathrm{~s} \pm 2.8 \mathrm{~s}$ \\
$d t_{32}$ & $-10.0 \mathrm{~s} \pm 4.4 \mathrm{~s}$ & $-16.8 \mathrm{~s} \pm 3.0 \mathrm{~s}$ \\
$d t_{41}$ & $9.0 \mathrm{~s} \pm 10.8 \mathrm{~s}$ & $2.2 \mathrm{~s} \pm 5.8 \mathrm{~s}$ \\
$d t_{42}$ & $12.4 \mathrm{~s} \pm 5.4 \mathrm{~s}$ & $10.2 \mathrm{~s} \pm 5.0 \mathrm{~s}$ \\
$d t_{43}$ & $22.8 \mathrm{~s} \pm 11.4 \mathrm{~s}$ & $24.6 \mathrm{~s} \pm 4.8 \mathrm{~s}$ \\
\hline
\end{tabular}

FTE at 19:38 UT was $(282,-7,39)_{\text {LMN }} \mathrm{km} \mathrm{s}^{-1}$. We used the procedure described by Fear et al. (2007) to set up a distribution of erroneous time differences (based on the uncertainty values given in Table 1) to check the robustness of these results. $90 \%$ of the velocities determined from the erroneous time differences were within $9.3^{\circ}$ and $61 \mathrm{~km} \mathrm{~s}^{-1}$ of the velocity vector quoted above for FTE 2 , and within $3.3^{\circ}$ and $14 \mathrm{~km} \mathrm{~s}^{-1}$ for FTE 3 . The two velocities were only $2^{\circ}$ and $8^{\circ}$, respectively, from the LM plane, which gives further confidence in these results and the determination of the magnetopause normal.

Thus both FTEs moved almost entirely in the L direction. (If the velocities are projected into the $\hat{\boldsymbol{l}}-\hat{\boldsymbol{m}}$ plane, they lie within $14^{\circ}$ and $2^{\circ}$, respectively, of $\hat{\boldsymbol{l}}$.) This motion is directed upward in the lefthand and middle panels of Fig. 4, and a motion out of the plane in the righthand panel, as indicated next to each panel. Using the unit vector of the typical magnetosheath magnetic field observed by Cluster 2 between 19:20 and 19:50 UT [ $\boldsymbol{B}_{S H}=(-15,7,-2)_{\text {LMN }}$ nT] and the ion density and bulk velocity observed by Cluster 1 on entry to the magnetosheath at 19:48 UT $\left[n=15 \mathrm{~cm}^{-3}\right.$, $\left.\boldsymbol{V}_{S H}=(296,-34,-2)_{\mathrm{LMN}} \mathrm{km} \mathrm{s}^{-1}\right]$, it is possible to evaluate the expression derived by Cowley and Owen (1989) for the velocity of a reconnected magnetic field line connected to the Southern Hemisphere at this point $\left[\boldsymbol{V}_{\mathrm{HTS}}=\boldsymbol{V}_{S H}-V_{A} \hat{\boldsymbol{B}}_{S H}\right.$, where $V_{A}$ is the Alfvén speed]. We evaluated this velocity to be $(212,4,-11)_{\mathrm{LMN}} \mathrm{km} \mathrm{s}^{-1}$. This compares well in direction with the observed FTE velocities (the angular differences between $\boldsymbol{V}_{\text {HTS }}$ and the observed velocities at 19:33 and 19:38 UT are $14^{\circ}$ and $11^{\circ}$, respectively), and the observed FTE speed at 19:38 UT is similar (the ratio of the observed to theoretical speeds is 1.3). However, the observed FTE speed at 19:33 UT is nearly double the theoretical value.

Since Clusters 1 and 3 entered onto open magnetic field lines, the ion velocities observed by these two spacecraft can be compared with the ion outflow velocity predicted by a second expression derived by Cowley and Owen (1989) $\left[\boldsymbol{V}_{B L}=\boldsymbol{V}_{S H}+V_{A}\left(\hat{\boldsymbol{B}}_{B L}-\hat{\boldsymbol{B}}_{S H}\right)\right] . \boldsymbol{B}_{B L}$ is the magnetic field of the boundary layer just inside the magnetopause, which was taken by Cowley and Owen (1989) to have the same direction as the magnetospheric field but a suppressed magnitude. Only the unit vector is required in this expression, and we use the magnetospheric magnetic field observed by Cluster 3 just before the first FTE $\left[(21,20,2)_{\text {LMN }}\right.$ nT], which predicts an outflow velocity of $(145,-59,-15)_{\text {LMN }} \mathrm{km} \mathrm{s}^{-1}$ for ions on an open magnetic field line that is connected to the Southern Hemisphere. This compares well in direction with the peak ion flows observed in the FTEs at 19:22 and 19:38 UT by Cluster $1\left(24^{\circ}\right.$ and $\left.20^{\circ}\right)$ and Cluster 3 (both $8^{\circ}$ ). However, the observed peak ion flow speeds (320$385 \mathrm{~km} \mathrm{~s}^{-1}$ ) are again considerably higher than the calculated outflow speed $\left(160 \mathrm{~km} \mathrm{~s}^{-1}\right)$.

\subsection{FTE scale size}

The information above can be used to determine the scale size of the latter two FTEs in all three dimensions. The scale size in the direction of motion of the FTE, $D_{V}$, is approximately its scale size in the L direction $\left(D_{L}\right)$, and can be calculated by multiplying the duration of the FTE by its speed. The speed is determined from multi-spacecraft timing analysis, as discussed in Sect. 4.4. The speeds of the FTEs observed at 19:33 and 19:38 UT were 411 and $285 \mathrm{~km} \mathrm{~s}^{-1}$, respectively. The durations of the FTEs were determined from the Cluster 3 PEACE signatures as these suffered from the fewest data gaps, and the presence of magnetosheath electrons in the magnetosphere indicates that the spacecraft was on open magnetic field lines. The duration was taken to be the length of time during which the differential energy flux observed by the Cluster 3 PEACE LEEA sensor was above $10^{-5} \mathrm{ergs} /\left(\mathrm{cm}^{-2} \mathrm{~s} \mathrm{sreV}\right)$ at $100 \mathrm{eV}$. The durations of the FTEs observed at 19:33 and 19:38 UT were $25 \mathrm{~s}$ and $22 \mathrm{~s}$, respectively. When multiplied by the FTE speeds, these give scale sizes $D_{V}=10300 \mathrm{~km}$ and $6200 \mathrm{~km}$. If we assume an uncertainty in the determined velocities of $10 \%$, and consider that the uncertainty in the timing of both the start and end of the electron signatures is $4 \mathrm{~s}$ (the temporal resolution of the PEACE LEEA sensor, which is the spacecraft spin period), then we estimate the uncertainty on the two $D_{V}$ values to be $2600 \mathrm{~km}$ and $1700 \mathrm{~km}$, respectively.

These scale sizes can be confirmed qualitatively by noting that the $B_{N}$ and electron signatures observed by Cluster 3 at 19:38 UT had just finished by the time they started at Cluster 1 (Fig. 8); these two spacecraft were at a similar distance from the magnetopause (Fig. 4), and were separated in the L direction by $6700 \mathrm{~km}$, which was equal to $D_{V}$ within the stated uncertainty. On the other hand, there was some overlap between the bipolar $B_{N}$ signatures observed by Clusters 1 and 3 at 19:33 UT, which is consistent with a slightly larger $D_{L}$ scale size.

The scale of both FTEs perpendicular to their velocities but within the magnetopause plane (i.e. $D_{M}$ ) can be constrained by the fact that they were both observed by all four spacecraft. Consequently, the azimuthal (M) extent of the FTE must be at least equal to the azimuthal scale of the Cluster tetrahedron $(10500 \mathrm{~km})$. Therefore the azimuthal scale of both events is $70 \%$ larger than the poleward extent of the 
FTE observed at 19:38 UT, and at least comparable to the poleward extent of the 19:33 UT FTE.

Cluster 2 observed the core of the 19:33 and 19:38 UT FTEs in the magnetosheath, and Clusters 1 and 3 observed the core in the magnetosphere, as evidenced by the presence of electron signatures (Figs. 7 and 8). Cluster 4, deeper in the magnetosphere, observed no electron signature during either FTE, and hence entered onto regions of draped magnetospheric magnetic field but did not enter onto reconnected field lines in the core. Consequently, we conclude that the minimum extent of both FTEs normal to the magnetopause is given by the separation of Clusters 1 and 2 in the $\mathrm{N}$ direction $(6300 \mathrm{~km})$ whilst the maximum normal extent is the separation of Clusters 2 and $4(11000 \mathrm{~km})$. Either FTE may extend deeper into the magnetosheath than the location of Cluster 2, but the $B_{N}$ signatures observed by both Cluster 2 and Cluster 4 at 19:38 UT were weak, so the extent of the final FTE in $\mathrm{N}$ is unlikely to be significantly outside these bounds.

Since the bipolar $B_{N}$ signature observed by Cluster 4 at 19:30 UT was too weak to attempt multi-spacecraft timing analysis, it is not possible to derive the poleward extent of this FTE. However, the presence of even a weak signature at Cluster 4 indicates that this FTE also extends azimuthally by at least $10500 \mathrm{~km}$.

\section{Discussion}

Milan et al. (2000) showed from ionospheric observations that time-varying reconnection may take place coherently over large extents of the magnetopause. However, in situ observations from multiple satellites at large separations are required to determine whether individual, coherent FTEs form along long extents of the magnetopause, or whether the ionospheric observations are due to a large number of smaller FTEs. Our observations have provided a minimum azimuthal scale size for three FTEs (assuming the FTE at 19:30 UT also moved predominantly poleward). However, larger spacecraft separations (possibly with more than four satellites) would be required to determine an upper limit for the azimuthal extent of each FTE.

The analysis above shows that the azimuthal extent of the FTE observed at 19:38 UT on 27 January 2006 was significantly greater than its poleward extent. Whilst the azimuthal and poleward scale sizes deduced for the FTE observed at 19:33 UT were approximately equal, the azimuthal scale is a minimum possible value, and it is still likely that the 19:33 UT FTE extended further azimuthally than poleward.

A comparison with Fig. 1 suggests that such a structure is more likely to be consistent with the multiple X-line or single X-line models (Lee and Fu, 1985; Southwood et al., 1988; Scholer, 1988a) than with the elbow-shaped flux rope model (Russell and Elphic, 1978), since if the magnetic shear is large across the magnetopause, the elbow-shaped flux tube has a small azimuthal extent in comparison with its longitudinal size whereas the single and multiple $\mathrm{X}$-line models can allow a large azimuthal extent. This interpretation assumes that the same FTE was observed by all four spacecraft; whilst we do not have continuous in situ coverage along the $\mathrm{M}$ direction (i.e. the Cluster spacecraft provide observations at discrete points), we note that the three FTEs with the largest $B_{N}$ variations observed by Cluster 1 between 19:28 and 19:40 UT exhibited signatures on all four spacecraft. We therefore consider it unlikely that in each case two or more different FTEs were observed at the same time by different spacecraft in the Cluster quartet.

The positions at which magnetosheath FTE signatures and magnetospheric FTE signatures were observed are also inconsistent with a simple interpretation of the elbow-shaped flux tube model. Figure 9a shows the relative positions of the four Cluster spacecraft in the L-M plane (coloured circles), with a sketch of an FTE assuming the elbow-shaped flux tube model. In this figure, the thin black and red arrows show the directions of the magnetospheric and magnetosheath magnetic fields, within the magnetopause plane. The magnetospheric magnetic field is oriented at $45^{\circ}$ to $\hat{\boldsymbol{l}}$, since $B_{L} \approx B_{M}$ (see Fig. 5), and the magnetosheath magnetic field is oriented at $155^{\circ}$ to $\hat{l}$. The observation of heated electrons parallel to the magnetic field in the magnetosheath by Cluster 2 indicates that the FTE was magnetically connected to the Southern Hemisphere (Figs. 6, 7 and 8). Since the FTEs were observed in the Northern Hemisphere, the force exerted on the flux tube by the magnetosheath flow opposed the magnetic tension due to the kink in the magnetic field, and this scenario is sketched. The FTE is sketched as it would be soon after reconnection. The FTE velocity marked in the figure applies at the hole, where the flux threads the magnetopause; away from the hole only the force exerted by the magnetosheath flow acts on the magnetosheath arm, and so this arm will have a larger velocity than at the hole. Consequently, the magnetosheath arm will soon "lead" the hole (not shown).

In Fig. 9a, the magnetosheath arm is contained entirely within the magnetosheath, and the magnetospheric arm is contained entirely within the magnetosphere. The two arms are linked through a hole in the magnetopause, which moves poleward as the FTE propagates and peels flux. Since Clusters 1 and 3 observed a magnetospheric FTE, in the context of this model they must have been located in a position where they would have observed the magnetospheric arm. Similarly Cluster 2 observed a magnetosheath FTE and therefore must have observed the magnetosheath arm. Cluster 2 was located dawnward of Cluster 3, and its location has been marked accordingly in Fig. 9a. However, Cluster 4 was located even further dawnward than Cluster 2, and so would be expected to observe the magnetosheath arm. This is not consistent with the observation of a magnetospheric FTE at Cluster 4. In the scenario sketched in Fig. 9a, Clusters 2 and 4 would 

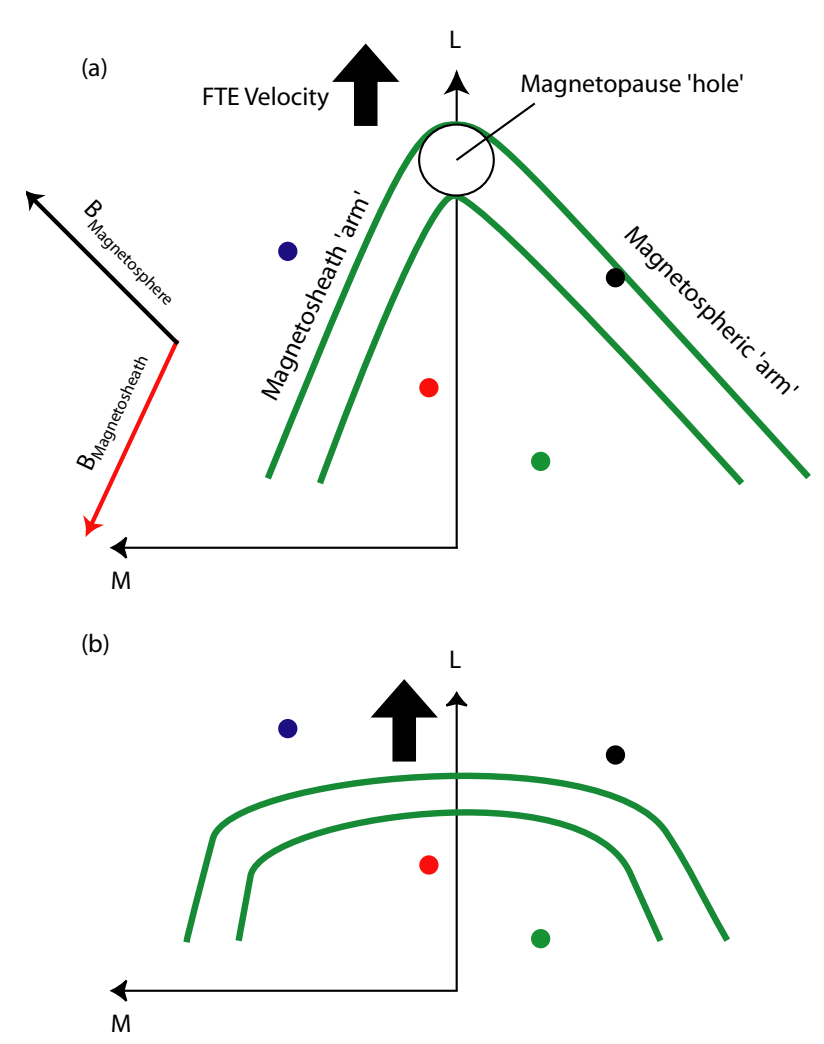

Fig. 9. (a) A sketch of a reconnected flux tube ("elbow-shaped flux rope model" FTE) formed by the magnetic geometry shown in Fig. 5. The figure shows a view of the magnetopause plane as it would be seen from the magnetosheath. The FTE is connected to the Southern Hemisphere, and moves upward in the L direction (indicated by the thick black arrow), and peels away flux such that the open flux always passes through a "hole" in the magnetopause, and the hole moves poleward. The locations of the Cluster spacecraft are marked by coloured dots (using the same colour scale as Fig. 2). The location of Cluster 4 is inconsistent with observing the magnetospheric "arm" of this event if Cluster 2 observed the magnetosheath "arm". A less simplistic interpretation of this model is shown in (b), where the kink in the flux tube relaxes to form an intermediate section which is embedded on the magnetopause (as sketched by Farrugia et al., 1987). Unless the magnetic shear across the magnetopause is much higher, this can provide a large azimuthal extent to an FTE formed by the process sketched by Russell and Elphic (1978).

need to be near the magnetopause hole for all four spacecraft to observe FTE signatures. Since Cluster 2 entered onto open magnetic field lines, one would expect the main component of the observed magnetic field to be normal to the magnetopause $\left(B_{N}>0\right)$. However, Cluster 2 observed bipolar $B_{N}$ signatures during the three highlighted FTEs, and the largest magnetic field component inside the FTEs was $B_{M}$ (Fig. 5).

If the flux tube was connected to the Northern Hemisphere (which would not explain the sense of the magnetosheath electron signatures), then the flux tube in Fig. 9a would be mirrored about both the $\mathrm{L}$ and $\mathrm{M}$ axes; the observation of magnetospheric and magnetosheath FTE signatures by Clusters 4 and 2, respectively, could be consistent with observations of the relevant FTE arms, but the observation of magnetospheric FTEs by Clusters 1 and 3 would not be. In the single X-line model, the FTE structure consists of a thickened magnetopause layer which could extend largely in the $\mathrm{M}$ direction, and would cause both magnetospheric and magnetosheath FTE signatures along its entire length, and would therefore be consistent with the observed signatures. Similarly, in the multiple X-line model the flux rope would extend largely in the $\mathrm{M}$ direction. Since this entire flux rope is, by definition, embedded in the magnetopause, it would also cause both magnetospheric and magnetosheath FTE signatures along its entire length, and would be consistent with the observations.

Therefore, the observations are consistent with an FTE generated by either the single or multiple X-line model, but not the above interpretation of the elbow-shaped flux tube model. However, there is another interpretation of the observations, which would be consistent with an FTE as Russell and Elphic (1978) broadly envisaged. Between 19:30 and 19:37 UT, the interval in which the three largest FTEs were observed, the magnetic shear across the magnetopause varied between $100^{\circ}$ and $130^{\circ}$. Consequently, the two arms of the flux tubes in Fig. 9a both had components along M. If, rather than simply peeling off flux as the FTE propagated (as implied in the sketch by Russell and Elphic, 1978), the flux tube kink relaxed to form an elongated "U" rather than a sharp "V", the scenario would be more like that depicted in Fig. 9b. In this sketch, the magnetopause hole has become much more elongated, as the kink has relaxed and therefore a significant part of the flux tube has been embedded in the magnetopause (as, for example, sketched by Farrugia et al., 1987). This part of the FTE structure, and not the magnetosheath and magnetospheric arms, would cause FTE signatures to be observed either side of the magnetopause. Furthermore, this part of the structure could have a large azimuthal extent in comparison with its poleward scale size, and could extend past all four Cluster spacecraft, explaining the present observations.

Since the magnetic shear is comparatively low $\left(100^{\circ}-\right.$ $130^{\circ}$ ), a structure such as that in Fig. $9 \mathrm{~b}$ would be difficult to distinguish from a flux rope formed by multiple X-line reconnection, or from the structure formed in the single $\mathrm{X}$-line model. This ambiguity could be removed in the case of an FTE which occurs when the magnetic shear is much closer to $180^{\circ}$, since the magnetospheric and magnetosheath arms would then be parallel to each other. We hope to address this issue in a future study.

The reductions and positive excursions in the $B_{L}$ components and the enhancements in $B_{M}$ in the magnetosheath FTEs observed by Cluster 2 in Figs. 6-8 are consistent with a rotation of the magnetic field towards magnetospheric values as reconnected magnetic field lines are observed, as might be expected in either of the long X-line models (or the situation 
in Fig. 9b). Similarly, the reduction in the $B_{M}$ component during the magnetospheric FTEs observed by Clusters 1 and 3 is consistent with a rotation towards a magnetospheric value (although the $B_{L}$ enhancement is not, and warrants further study).

\section{Conclusions}

We have presented observations of flux transfer events at a $10000 \mathrm{~km}$ scale length. A large number of FTEs were observed as the Cluster quartet crossed the Northern Hemisphere magnetopause between 19:20 and 19:50 UT on 27 January 2006; three FTEs were observed by all four spacecraft at different distances from the magnetopause. All three FTEs were observed from the magnetosheath by Cluster 2, which entered onto the open magnetic field lines contained within the structure. The other three spacecraft were located within the magnetosphere; Cluster 1 entered onto open magnetic field lines in all three cases, Cluster 4 remained on closed magnetospheric magnetic field lines and observed only the draping of flux around the FTE core in all three cases, and Cluster 3 observed open magnetic field lines in two of the FTEs. These two FTEs were large enough to exhibit a clear enough bipolar $B_{N}$ signature on all four spacecraft for the velocity of the FTEs to be determined from multi-spacecraft timing analysis. Both FTEs were found to be moving largely in the $\mathrm{L}$ direction (northward). Magnetosheath electron observations indicate that the open field lines were connected to the Southern Hemisphere, so the force exerted on the FTE by the magnetosheath flow overpowered the southward-directed magnetic tension in the flux rope. Combining the duration of the FTE electron signatures with the speed of the structure provided the poleward scale sizes of these two FTEs $(10300$ and $6200 \mathrm{~km})$. The fact that the three largest events were observed at all four spacecraft shows that their azimuthal scale sizes were at least $10500 \mathrm{~km}$. Consequently, one FTE was certainly extended further azimuthally than poleward, and a second had an azimuthal extent that was at least comparable, but probably larger than its poleward size. The FTEs observed by all four spacecraft were consistent with being formed according to the single or multiple X-line models proposed by Southwood et al. (1988), Scholer (1988a) and Lee and Fu (1985), but not by a simple interpretation of the elbow-shaped flux tube model originally suggested by Russell and Elphic (1978, 1979). However, the observations can be interpreted in terms of an elbow-shaped flux tube which relaxes, causing the flux tube to become embedded in the magnetopause for a larger extent; this possibility could be confirmed or excluded by future large-scale multi-spacecraft observations of FTEs when the magnetic shear across the magnetopause is much closer to $180^{\circ}$.

Acknowledgements. The authors thank the Cluster FGM, PEACE and CIS instrument teams. Geotail magnetic field data were pro- vided by T. Nagai through DARTS at Institute of Space and Astronautical Science, JAXA in Japan. Geotail plasma data were provided by L. Frank at the University of Iowa through CDAWeb. Data analysis was carried out with the QSAS science analysis system provided by the United Kingdom Cluster Science Centre (Imperial College London and Queen Mary, University of London) supported by the Science and Technology Facilities Council (STFC). Work at the University of Leicester was supported by STFC grant number PP/E000983/1.

Topical Editor R. Nakamura thanks D. Sibeck and J. A. Slavin for their help in evaluating this paper.

\section{References}

Amm, O., Donovan, E. F., Frey, H., Lester, M., Nakamura, R., Wild, J. A., Aikio, A., Dunlop, M., Kauristie, K., Marchaudon, A., McCrea, I. W., Opgenoorth, H.-J., and Strømme, A.: Coordinated studies of the geospace environment using Cluster, satellite and ground-based data: an interim review, Ann. Geophys., 23, 2129-2170, 2005, http://www.ann-geophys.net/23/2129/2005/.

Balogh, A., Carr, C. M., Acuña, M. H., Dunlop, M. W., Beek, T. J., Brown, P., Fornaçon, K.-H., Georgescu, E., Glassmeier, K.-H., Harris, J., Musmann, G., Oddy, T., and Schwingenschuh, K.: The Cluster Magnetic Field Investigation: Overview of in-flight performance and initial results, Ann. Geophys., 19, 1207-1217, 2001, http://www.ann-geophys.net/19/1207/2001/.

Cowley, S. W. H.: The causes of convection in the Earth's magnetosphere: A review of developments during the IMS, Rev. Geophys. Space Phys., 20, 531-565, 1982.

Cowley, S. W. H. and Owen, C. J.: A simple illustrative model of open flux tube motion over the dayside magnetopause, Planet. Space Sci., 37, 1461-1475, 1989.

Daly, P. W., Rijnbeek, R. P., Sckopke, N., Russell, C. T., and Saunders, M. A.: The distribution of reconnection geometry in flux transfer events using energetic ion, plasma and magnetic data, J. Geophys. Res., 89, 3843-3854, 1984.

Dunlop, M. W., Taylor, M. G. G. T., Davies, J. A., Owen, C. J., Pitout, F., Fazakerley, A. N., Pu, Z., H., L., Bogdanova, Y. V., Zong, Q.-G., Shen, C., Nykyri, K., Lavraud, B., Milan, S. E., Phan, T. D., Rème, H., P., E. C., Carr, C. M., Cargill, P., Lockwood, M., and Sonnerup, B.: Coordinated Cluster/Double Star observations of dayside reconnection signatures, Ann. Geophys., 23, 2867-2875, 2005, http://www.anngeophys.net/23/2867/2005/.

Elphic, R. C. and Southwood, D. J.: Simultaneous measurements of the magnetopause and flux transfer events at widely separated sites by AMPTE UKS and ISEE 1 and 2, J. Geophys. Res., 92, 13 666-13 672, 1987.

Farrugia, C. J., Southwood, D. J., Cowley, S. W. H., Rijnbeek, R. P., and Daly, P. W.: Two-regime flux transfer events, Planet. Space Sci., 35, 737-744, 1987.

Farrugia, C. J., Rijnbeek, R. P., Saunders, M. A., Southwood, D. J., Rodgers, D. J., Smith, M. F., Chaloner, C. P., Hall, D. S., Christiansen, P. J., and Woolliscroft, L. J. C.: A multi-instrument study of flux transfer event structure, J. Geophys. Res., 93, 1446514477, 1988.

Fasel, G. J.: Dayside poleward moving auroral forms: A statistical study, J. Geophys. Res., 100, 11 891-11 905, 1995. 
Fear, R. C., Fazakerley, A. N., Owen, C. J., and Lucek, E. A.: A survey of flux transfer events observed by Cluster during strongly northward IMF, Geophys. Res. Lett., 32, L18105, doi:10.1029/ 2005GL023811, 2005.

Fear, R. C., Milan, S. E., Fazakerley, A. N., Owen, C. J., Asikainen, T., Taylor, M. G. G. T., Lucek, E. A., Rème, H., Dandouras, I., and Daly, P. W.: Motion of flux transfer events: a test of the Cooling model, Ann. Geophys., 25, 1669-1690, 2007, http://www.ann-geophys.net/25/1669/2007/.

Frank, L. A., Ackerson, K. L., Paterson, W. R., Lee, J. A., English, M. R., and Pickett, G. L.: The comprehensive plasma instrumentation (CPI) for the Geotail spacecraft, J. Geomag. Geoelectr., 46, 23-37, 1994.

Haerendel, G., Paschmann, G., Sckopke, N., Rosenbauer, H., and Hedgecock, P. C.: The frontside boundary layer of the magnetosphere and the problem of reconnection, J. Geophys. Res., 83, 3195-3216, 1978.

Harvey, C. C.: Spatial gradients and the volumetric tensor, in: Analysis Methods for Multi-Spacecraft Data, edited by: Paschmann, G. and Daly, P. W., pp. 307-348, ISSI, 1998.

Hasegawa, H., Sonnerup, B. U. O., Owen, C. J., Klecker, B., Paschmann, G., Balogh, A., and Rème, H.: The structure of flux transfer events recovered from Cluster data, Ann. Geophys., 24, 603-618, 2006, http://www.ann-geophys.net/24/603/2006/.

Heikkila, W. J.: Impulsive plasma transport through the magnetosphere, Geophys. Res. Lett., 9, 159-162, 1982.

Johnstone, A. D., Alsop, C., Burdge, S., Carter, P. J., Coates, A. J., Coker, A. J., Fazakerley, A. N., Grande, M., Gowen, R. A., Gurgiolo, C., Hancock, B. K., Narheim, B., Preece, A., Sheather, P. H., Winningham, J. D., and Woodliffe, R. D.: PEACE: A Plasma Electron And Current Experiment, Space Sci. Rev., 79, 351-398, 1997.

Kokubun, S., Yamamoto, T., Acuña, M. H., Hayashi, K., Shiokawa, K., and Kawano, H.: The Geotail magnetic field experiment, J. Geomag. Geoelectr., 46, 7-21, 1994.

LaBelle, J., Treumann, R. A., Haerendel, G., Bauer, O. H., Paschmann, G., Baumjohann, W., Lühr, H., Anderson, R. R., Koons, H. C., and Holzworth, R. H.: AMPTE IRM observations of waves associated with flux transfer events in the magnetosphere, J. Geophys. Res., 92, 5827-5843, 1987.

Le, G., Zheng, Y., Russell, C. T., Pfaff, R. F., Slavin, J. A., Lin, N., Mozer, F., Parks, G., Wilber, M., Petrinec, S. M., Lucek, E. A., and Rème, H.: Flux transfer events simultaneously observed by Polar and Cluster: Flux rope in the subsolar region and flux tube addition to the polar cusp, J. Geophys. Res., 113, A01205, doi: 10.1029/2007JA012377, 2008.

Lee, L. C. and Fu, Z. F.: A theory of magnetic flux transfer at the Earth's magnetopause, Geophys. Res. Lett., 12, 105-108, 1985.

Lemaire, J. and Roth, M.: Penetration of solar wind plasma elements into the magnetosphere, J. Atmos. Terr. Phys., 40, 331335, 1978.

Lemaire, J., Rycroft, M. J., and Roth, M.: Control of impulsive plasma penetration of solar wind irregularities into the magnetosphere by the interplanetary magnetic field, Planet. Space Sci., 27, 47-57, 1979.

Lockwood, M. and Davis, C. J.: On the longitudinal extent of magnetopause reconnection pulses, Ann. Geophys., 14, 865-878, 1996, http://www.ann-geophys.net/14/865/1996/.

Marchaudon, A., Cerisier, J., Bosqued, J., Dunlop, M., Wild, J.,
Décréau, P., Förster, M., Fontaine, D., and Laakso, H.: Transient plasma injections in the dayside magnetosphere: One-toone correlated observations by Cluster and SuperDARN, Ann. Geophys., 22, 141-158, 2004,

http://www.ann-geophys.net/22/141/2004/.

Milan, S. E., Lester, M., Cowley, S. W. H., and Brittnacher, M.: Convection and auroral response to a southward turning of the IMF: Polar UVI, CUTLASS, and IMAGE signatures of transient magnetic flux transfer at the magnetopause, J. Geophys. Res., 105, 15 741-15 756, doi:10.1029/2000JA900022, 2000.

Owen, C. J. and Cowley, S. W. H.: Simple models of timedependent reconnection in a collision-free plasma with an application to substorms in the geomagnetic tail, Planet. Space Sci., 35, 451-466, doi:10.1016/0032-0633(87)90102-4, 1987.

Owen, C. J. and Cowley, S. W. H.: Heikkila's mechanism for impulsive plasma transport through the magnetosphere: A reexamination, J. Geophys. Res., 96, 5565-5574, 1991.

Owen, C. J., Fazakerley, A. N., Carter, P. J., Coates, A. J., Krauklis, I. C., Szita, S., Taylor, M. G. G. T., Travnicek, P., Watson, G., Wilson, R. J., Balogh, A., and Dunlop, M. W.: Cluster PEACE observations of electrons during magnetospheric flux transfer events, Ann. Geophys., 19, 1509-1522, 2001, http://www.ann-geophys.net/19/1509/2001/.

Owen, C. J., Marchaudon, A., Dunlop, M. W., Fazakerley, A. N., Bosqued, J.-M., Dewhurst, J. P., Fear, R. C., Fuselier, S. A., Balogh, A., and Rème, H.: Cluster observations of 'crater' flux transfer events at the dayside high-latitude magnetopause, J. Geophys. Res., 113, A07S04, doi:10.1029/2007JA012701, 2008.

Paschmann, G., Haerendel, G., Papamastorakis, I., Sckopke, N., Bame, S. J., Gosling, J. T., and Russell, C. T.: Plasma and magnetic field characteristics of magnetic flux transfer events, J. Geophys. Res., 87, 2159-2168, 1982.

Peredo, M., Slavin, J. A., Mazur, E., and Curtis, S. A.: Threedimensional position and shape of the bow shock and their variation with Alfvenic, sonic and magnetosonic Mach numbers and interplanetary magnetic field orientation, J. Geophys. Res., 100, 7907-7916, 1995.

Pinnock, M., Rodger, A. S., Dudeney, J. R., Baker, K. B., Newell, P. T., Greenwald, R. A., and Greenspan, M. E.: Observations of an enhanced convection channel in the cusp ionosphere, J. Geophys. Res., 98, 3767-3776, 1993.

Pinnock, M., Rodger, A. S., Dudeney, J. R., Rich, F., and Baker, K. B.: High spatial and temporal resolution observations of the ionospheric cusp, Ann. Geophys., 13, 919-925, 1995, http://www.ann-geophys.net/13/919/1995/.

Provan, G., Yeoman, T. K., and Milan, S. E.: CUTLASS Finland radar observations of the ionospheric signatures of flux transfer events and the resulting plasma flows, Ann. Geophys., 16, 14111422, 1998, http://www.ann-geophys.net/16/1411/1998/.

Rijnbeek, R. P. and Cowley, S. W. H.: Magnetospheric flux erosion events are flux transfer events, Nature, 309, 135-138, 1984.

Rijnbeek, R. P., Cowley, S. W. H., Southwood, D. J., and Russell, C. T.: Observations of reverse polarity flux transfer events at the Earth's magnetopause, Nature, 300, 23-26, 1982.

Rijnbeek, R. P., Cowley, S. W. H., Southwood, D. J., and Russell, C. T.: A survey of dayside flux transfer events observed by ISEE1 and ISEE-2 magnetometers, J. Geophys. Res., 89, 786-800, 1984.

Rijnbeek, R. P., Farrugia, C. J., Southwood, D. J., Dunlop, M. W., 
Mier-Jedrzejowicz, W. A. C., Chaloner, C. P., Hall, D. S., and Smith, M. F.: A magnetic boundary signature within flux transfer events, Planet. Space Sci., 35, 871-878, 1987.

Roelof, E. C. and Sibeck, D. G.: Magnetopause shape as a bivariate function of interplanetary magnetic field $B_{Z}$ and solar wind dynamic pressure, J. Geophys. Res., 98, 21 421-21 450, 1993.

Russell, C. T. and Elphic, R. C.: Initial ISEE magnetometer results: Magnetopause observations, Space Sci. Rev., 22, 681-715, 1978.

Russell, C. T. and Elphic, R. C.: ISEE observations of flux transfer events at the dayside magnetopause, Geophys. Res. Lett., 6, 3336, 1979.

Russell, C. T., Mellott, M. M., Smith, E. J., and King, J. H.: Multiple spacecraft observations of interplanetary shocks: Four spacecraft determination of shock normals, J. Geophys. Res., 88, 4739-4748, 1983.

Sandholt, P. E., Deehr, C. S., Egeland, A., Lybekk, B., Viereck, R., and Romick, G. J.: Signatures in the dayside aurora of plasma transfer from the magnetosheath, J. Geophys. Res., 91, $10063-$ $10079,1986$.

Sandholt, P. E., Lockwood, M., Denig, W. F., Elphic, R. C., and Leontjev, S.: Dynamical auroral structure in the vicinity of the polar cusp: Multipoint observations during southward and northward IMF, Ann. Geophys., 10, 483-497, 1992,

http://www.ann-geophys.net/10/483/1992/.

Saunders, M. A., Russell, C. T., and Sckopke, N.: Flux transfer events: Scale size and interior structure, Geophys. Res. Lett., 11, 131-134, 1984.

Scholer, M.: Magnetic flux transfer at the magnetopause based on single X-line bursty reconnection, Geophys. Res. Lett., 15, 291294, 1988a.

Scholer, M.: Strong core magnetic fields in magnetopause flux transfer events, Geophys. Res. Lett., 15, 748-751, 1988b.

Scholer, M.: Models of flux transfer events, in: Physics of the Magnetopause, edited by: Song, P., Sonnerup, B. U. Ö., and Thomsen, M. F., vol. 90 of Geophysical Monograph, pp. 235-245, American Geophysical Union, Washington D.C., 1995.

Shue, J.-H., Song, P., Russell, C. T., Steinberg, J. T., Chao, J. K., Zastenker, G., Vaisberg, O. L., Kokubun, S., Singer, H. J., Detman, T. R., and Kawano, H.: Magnetopause location under extreme solar wind conditions, J. Geophys. Res., 103, 17 691-17 700, doi: 10.1029/98JA01103, 1998.

Sibeck, D. G.: A model for the transient magnetospheric response to sudden solar wind dynamic pressure variations, J. Geophys. Res., 95, 3755-3771, 1990.

Sibeck, D. G.: Transient events in the outer magnetosphere: Boundary waves or flux transfer events?, J. Geophys. Res., 97, 40094026, 1992.

Smith, M. F. and Curran, D. B.: On the correlation between a magnetopause penetration parameter and FTE occurrence, Ann. Geophys., 8, 579-582, 1990, http://www.anngeophys.net/8/579/1990/.

Smith, M. F. and Owen, C. J.: Temperature anisotropies in a magnetospheric FTE, Geophys. Res. Lett., 19, 1907-1910, 1992.

Sonnerup, B. U. Ö.: On the stress balance in flux transfer events, J. Geophys. Res., 92, 8613-8620, 1987.

Sonnerup, B. U. O. and Cahill Jr., L. J.: Magnetopause structure and attitude from Explorer 12 observations, J. Geophys. Res., 72, 171-183, 1967.

Sonnerup, B. U. O. and Scheible, M.: Minimum and Maximum
Variance Analysis, in: Analysis Methods for Multi-Spacecraft Data, edited by: Paschmann, G. and Daly, P. W., pp. 185-220, ISSI, 1998.

Southwood, D. J., Farrugia, C. J., and Saunders, M. A.: What are flux transfer events?, Planet. Space Sci., 36, 503-508, 1988.

Tsyganenko, N. A.: Modeling the Earth's magnetospheric magnetic field confined within a realistic magnetopause, J. Geophys. Res., 100, 5599-5612, 1995.

Wang, J., Dunlop, M. W., Pu, Z. Y., Zhou, X. Z., Zhang, X. G., Wei, Y., Fu, S. Y., Xiao, C. J., Fazakerley, A., Laakso, H., Taylor, M. G. G. T., Bogdanova, Y., Pitout, F., Davies, J., Zong, Q. G., Shen, C., Liu, Z. X., Carr, C., Perry, C., Rème, H., Dandouras, I., Escoubet, P., and Owen, C. J.: TC1 and Cluster observation of an FTE on 4 January 2005: A close conjunction, Geophys. Res. Lett., 34, L03106, doi:10.1029/2006GL028241, 2007.

Wang, Y. L., Elphic, R. C., Lavraud, B., Taylor, M. G. G. T., Birn, J., Raeder, J., Russell, C. T., Kawano, H., Zong, Q.-G., Zhang, H., Zhang, X. X., and Friedel, R. H.: Initial results of high-latitude magnetopause and low-latitude flank flux transfer events from 3 years of Cluster observations, J. Geophys. Res., 110, A11221, doi:10.1029/2005JA011150, 2005.

Wang, Y. L., Elphic, R. C., Lavraud, B., Taylor, M. G. G. T., Birn, J., Russell, C. T., Raeder, J., Kawano, H., and Zhang, X. X.: Dependence of flux transfer events on solar wind conditions from 3 years of Cluster observations, J. Geophys. Res., 111, A04224, doi:10.1029/2005JA011342, 2006.

Wild, J. A., Cowley, S. W. H., Davies, J. A., Khan, H., Lester, M., Milan, S. E., Provan, G., Yeoman, T. K., Balogh, A., Dunlop, M. W., Fornaçon, K.-H., and Georgescu, E.: First simultaneous observations of flux transfer events at the high-latitude magnetopause by the Cluster spacecraft and pulsed radar signatures in the conjugate ionosphere by the CUTLASS and EISCAT radars, Ann. Geophys., 19, 1491-1508, 2001, http://www.ann-geophys.net/19/1491/2001/.

Wild, J. A., Milan, S. E., Cowley, S. W. H., Dunlop, M. W., Owen, C. J., Bosqued, J. M., Taylor, M. G. G. T., Davies, J. A., Lester, M., Sato, N., Yukimatu, A. S., Fazakerley, A. N., Balogh, A., and Rème, H.: Coordinated interhemispheric SuperDARN radar observations of the ionospheric response to flux transfer events observed by the Cluster spacecraft at the high-latitude magnetopause, Ann. Geophys., 21, 1807-1826, 2003, http://www.ann-geophys.net/21/1807/2003/.

Wild, J. A., Milan, S. E., Cowley, S. W. H., Bosqued, J. M., Rème, H., Nagai, T., Kokubun, S., Saito, Y., Mukai, T., Davies, J. A., Cooling, B. M. A., Balogh, A., and Daly, P. W.: Simultaneous insitu observations of the signatures of dayside reconnection at the high- and low-latitude magnetopause, Ann. Geophys., 23, 445460, 2005a, http://www.ann-geophys.net/23/445/2005/.

Wild, J. A., Milan, S. E., Davies, J. A., Cowley, S. W. H., Carr, C. M., and Balogh, A.: Double Star, Cluster, and ground-based observations of magnetic reconnection during an interval of duskward oriented IMF: preliminary results, Ann. Geophys., 23, 2903-2907, 2005b, http://www.ann-geophys.net/23/2903/2005/.

Wild, J. A., Milan, S. E., Davies, J. A., Dunlop, M. W., Wright, D. M., Carr, C. M., Balogh, A., Rème, H., Fazakerley, A. N., and Marchaudon, A.: On the location of dayside magnetic reconnection during an interval of duskward oriented IMF, Ann. Geophys., 25, 219-238, 2007,

http://www.ann-geophys.net/25/219/2007/. 